\title{
Characterization and source apportionment of organic aerosol using offline aerosol mass spectrometry
}

\author{
K. R. Daellenbach ${ }^{1}$, C. Bozzetti ${ }^{1}$, A. Křepelová ${ }^{1}$, F. Canonaco ${ }^{1}$, R. Wolf ${ }^{1}$, P. Zotter ${ }^{1, a}$, P. Fermo ${ }^{4}$, M. Crippa ${ }^{1, b}$, \\ J. G. Slowik ${ }^{1}$, Y. Sosedova ${ }^{1}$, Y. Zhang ${ }^{1,2,3, \mathrm{c}}$, R.-J. Huang ${ }^{1}$, L. Poulain ${ }^{5}$, S. Szidat ${ }^{2}$, U. Baltensperger ${ }^{1}$, I. El Haddad ${ }^{1}$, \\ and A.S. H. Prévôt ${ }^{1}$ \\ ${ }^{1}$ Laboratory of Atmospheric Chemistry, Paul Scherrer Institute, 5232 Villigen, Switzerland \\ ${ }^{2}$ Department of Chemistry and Biochemistry \& Oeschger Centre for Climate Change Research, \\ University of Bern, 3012 Bern, Switzerland \\ ${ }^{3}$ Laboratory of Radiochemistry and Environmental Chemistry, Paul Scherrer Institute, 5232 Villigen PSI, Switzerland \\ ${ }^{4}$ Department of Chemistry, University of Milan, 20133 Milan, Italy \\ ${ }^{5}$ Leibniz Institute for Troposphärenforschung, Leipzig, Germany \\ ${ }^{a}$ now at: Lucerne School of Engineering and Architecture, Bioenergy Research, Lucerne University of Applied Sciences \\ and Arts, 6048 Horw, Switzerland \\ ${ }^{b}$ now at: EC Joint Research Centre, Institute for Environment and Sustainability, 21027 Ispra, Italy \\ ${ }^{c}$ now at: Yale-NUIST Center on Atmospheric Environment, Nanjing University of Information \\ Science and Technology, Nanjing 10044, China
}

Correspondence to: A. S. H. Prévôt (andre.prevot@psi.ch) and I. El Haddad (imad.el-haddad@psi.ch)

Received: 25 June 2015 - Published in Atmos. Meas. Tech. Discuss.: 11 August 2015

Revised: 24 November 2015 - Accepted: 1 December 2015 - Published: 15 January 2016

\begin{abstract}
Field deployments of the Aerodyne Aerosol Mass Spectrometer (AMS) have significantly advanced real-time measurements and source apportionment of non-refractory particulate matter. However, the cost and complex maintenance requirements of the AMS make its deployment at sufficient sites to determine regional characteristics impractical. Furthermore, the negligible transmission efficiency of the AMS inlet for supermicron particles significantly limits the characterization of their chemical nature and contributing sources. In this study, we utilize the AMS to characterize the water-soluble organic fingerprint of ambient particles collected onto conventional quartz filters, which are routinely sampled at many air quality sites. The method was applied to 256 particulate matter $(\mathrm{PM})$ filter samples $\left(\mathrm{PM}_{1}, \mathrm{PM}_{2.5}\right.$, and $\mathrm{PM}_{10}$, i.e., $\mathrm{PM}$ with aerodynamic diameters smaller than 1 , 2.5 , and $10 \mu \mathrm{m}$, respectively), collected at 16 urban and rural sites during summer and winter. We show that the results obtained by the present technique compare well with those from co-located online measurements, e.g., AMS or Aerosol Chemical Speciation Monitor (ACSM). The bulk recoveries of organic aerosol (60-91\%) achieved using this technique,
\end{abstract}

together with low detection limits $(0.8 \mu \mathrm{g}$ of organic aerosol on the analyzed filter fraction) allow its application to environmental samples. We will discuss the recovery variability of individual hydrocarbon ions, ions containing oxygen, and other ions. The performance of such data in source apportionment is assessed in comparison to ACSM data. Recoveries of organic components related to different sources as traffic, wood burning, and secondary organic aerosol are presented. This technique, while subjected to the limitations inherent to filter-based measurements (e.g., filter artifacts and limited time resolution) may be used to enhance the AMS capabilities in measuring size-fractionated, spatially resolved longterm data sets.

\section{Introduction}

Aerosols affect climate, air quality, ecosystems, and human health (Kelly et al., 2007; Griggs and Noguer, 2002). Organic aerosol (OA), a significant fraction of the dry particle mass (Jimenez et al. (2009) and references therein), is either di- 
Table 1. Filter samples and available supporting measurements used in this study.

\begin{tabular}{|c|c|c|c|c|c|}
\hline Location & $\begin{array}{l}\text { Campaign } \\
\text { period }\end{array}$ & $\begin{array}{l}\text { Sampling } \\
\text { duration }(\mathrm{h})\end{array}$ & Samples & Size & $\begin{array}{l}\text { Supporting } \\
\text { measurements }\end{array}$ \\
\hline \multirow[t]{3}{*}{ Zurich (urban background) } & Apr 2011 & 12 & 11 & $\mathrm{PM}_{1}$ & $\begin{array}{l}\mathrm{PM}_{2.5} \text { fingerprints and } \mathrm{OA}, \mathrm{SO}_{4}^{2-\mathrm{a}} \text {, } \\
\text { gas-phase measurements }(\mathrm{CO})\end{array}$ \\
\hline & Aug 2008-Jul 2009 & 24 & 42 & $\mathrm{PM}_{10}$ & $\mathrm{OC} / \mathrm{EC}$, ions \\
\hline & Feb 2011-Feb 2012 & 24 & 41 & $\mathrm{PM}_{10}$ & $\begin{array}{l}\mathrm{PM}_{1} \text { fingerprints and } \mathrm{OA}, \\
\mathrm{SO}_{4}^{2-\mathrm{b}}, \mathrm{eBC}, \mathrm{WSOC}\end{array}$ \\
\hline \multirow[t]{2}{*}{ Paris (urban core) } & Jul 2009 & 12 & 12 & $\mathrm{PM}_{1}$ & $\begin{array}{l}\mathrm{OC} / \mathrm{EC}, \mathrm{PM}_{1} \text { fingerprints } \\
\text { and } \mathrm{OA}, \mathrm{SO}_{4}^{2-} \mathrm{a}\end{array}$ \\
\hline & Jan-Feb 2010 & & & & \\
\hline 15 NABEL stations in Switzerland ${ }^{c}$ & $\begin{array}{l}\text { Dec 2007-Feb } 2008 \\
\text { Dec 2008-Feb } 2009\end{array}$ & 24 & 150 & $\mathrm{PM}_{10}$ & $\mathrm{OC} / \mathrm{EC}$, ions \\
\hline
\end{tabular}

rectly emitted (primary organic aerosol, POA), or formed in the atmosphere through gas-phase oxidation of anthropogenic and biogenic volatile organic compounds and subsequent condensation or nucleation (secondary organic aerosol, SOA). Characterization of OA chemical composition and sources is necessary for understanding the corresponding atmospheric processes and mitigating the adverse effects of aerosols. Previous studies have shown that OA contains a variety of organic species, including hydrocarbons, alcohols, aldehydes, and carboxylic acids. However, only about 10$30 \%$ of OA has been chemically speciated so far (Hoffmann et al., 2011).

The High-Resolution Time-of-Flight Aerosol Mass Spectrometer (HR-ToF-AMS, Aerodyne Research, Inc.) has been widely used for characterizing OA in both field and laboratory studies. This instrument couples thermal vaporization with electron ionization (EI, $70 \mathrm{eV}$ ) and provides quantitative mass spectra of non-refractory aerosol components including $\mathrm{OA}, \mathrm{NH}_{4}^{+}, \mathrm{NO}_{3}^{-}, \mathrm{SO}_{4}^{2-}$, and $\mathrm{Cl}^{-}$. Application of advanced factor-based receptor models such as positive matrix factorization (PMF, Paatero and Tapper, 1994) to these spectra has been proven effective in apportioning OA into different factors (e.g. Lanz et al., 2007, 2010; Jimenez et al., 2009; Zhang et al., 2011; Ng et al., 2010; Crippa et al., 2014). These factors are subsequently related to primary sources like biomass burning (BBOA), traffic (HOA), and cooking (COA), as well as oxygenated organic aerosol (OOA), which is often attributed to SOA.

The cost and complex operation required by the AMS makes its simultaneous long-term deployment at many sites impractical. Consequently, current data sets are typically limited to few weeks and specific sites or measurements from mobile platforms (Mohr et al., 2011). Recently, a robust, less expensive, Aerosol Chemical Speciation Monitor (ACSM, $\mathrm{Ng}$ et al., 2011b) and a time-of-flight aerosol chemical speciation monitor (ToF-ACSM, Fröhlich et al., 2013, 2015) were developed to overcome some of these shortcomings. How- ever, the low mass resolution of these instruments reduces their utility. Meanwhile, other studies have proposed the use of the HR-ToF-AMS for the analysis of aqueous or organic solvent extracts of filter samples, which are already routinely collected at many sites worldwide, offering a greater coverage than with ACSMs (Mihara and Mochida, 2011; Lee et al., 2011; Sun et al., 2011). While such methodologies may greatly extend the ability of the AMS to measure spatially resolved long-term data sets, the results obtained only pertain to a sub-fraction of the total organic aerosol and are subject to inherent artifacts of filter-based measurements. It is not clear whether this fraction adequately reflects the chemical nature of the entire bulk OA and whether these results may be used for OA source apportionment. Here, we have adopted such an approach based on measurements of the water-soluble organic fraction. We present a methodology to generalize the results to bulk OA, based on the analysis of 256 filter samples from 16 urban to rural sites during different seasons and its comparison to online measurements. These results are expected to significantly broaden the spatial, temporal, and particle size ranges accessible to AMS measurements of organic aerosol.

\section{Methods}

\subsection{Aerosol sampling}

Particulate matter (PM) of different sizes $\left(\mathrm{PM}_{1}, \mathrm{PM}_{2.5}\right.$, and $\mathrm{PM}_{10}$, representing aerodynamic particle sizes smaller than $1,2.5$, and $10 \mu \mathrm{m}$, respectively) were collected onto preheated $\left(800^{\circ} \mathrm{C}, 12 \mathrm{~h}\right)$ Pall quartz filters (diameter $\left.14.7 \mathrm{~cm}\right)$ using HiVol samplers $\left(500 \mathrm{~L} \mathrm{~min}^{-1}\right)$. Field blanks were collected using the same method as for the exposed filters. The filters were stored in sealed bags at $-18^{\circ} \mathrm{C}$ and only transported cooled. Before handling the filters, they were left at room temperature in the sealed bags in order to avoid condensation of volatile compounds on the cold sur- 
face (> $15 \mathrm{~min}$ ). The offline AMS analysis of the filters collected in April 2011 in Zurich were conducted in October 2011. The other filters were analyzed between April and October 2012. While samples were collected at different seasons at 16 sites including urban, suburban, and rural sites (Table 1), we will mainly focus on the Zurich data sets (filters evenly distributed in the years 2011-2012) because of the extensive supporting measurements performed there. Measurements on the remaining samples are used for the assessment of the bulk OA water solubility.

The urban background site Kaserne in Zurich is located in a park in the middle of the urban core of a densely populated area (1.2 million inhabitants, including surrounding communities). In addition to filter sampling, an Aerosol Chemical Speciation Monitor (ACSM) was operated with a $\mathrm{PM}_{1}$ (standard) aerodynamic lens in Zurich from February 2011 to February 2012 (Canonaco et al., 2013, 2015, 2016). The ACSM provides quantitative unit mass resolution (UMR) mass spectra with a time resolution of $30 \mathrm{~min}$. These mass spectra can be used to determine the concentration of species such as $\mathrm{OA}$ and $\mathrm{SO}_{4}^{2-}$, while the OA mass spectra are suitable for source apportionment (Ng et al., 2011b). At the same site, equivalent black carbon (eBC) was monitored using an aethalometer, AE 31 (Magee Scientific Inc.) (Hansen et al., 1984; Herich et al., 2011), and CO by non-dispersive Fouriertransform infrared spectroscopy (APNA 360, Horiba, Kyoto, Japan). During spring 2011, $\mathrm{PM}_{2.5}$ filter samples were also collected and a HR-ToF-AMS equipped with a $\left(\mathrm{PM}_{2.5}\right)$ lens (Williams et al., 2013) was operated at the same site.

During the winters of 2007/08 and 2008/09, offline AMS measurements $\left(\mathrm{PM}_{10}\right)$ were conducted for 15 sites spread over Switzerland including flatland and alpine sites with varying population density and local emissions. A yearly cycle (August 2008-July 2009) from the urban background station in Zurich described above completes this data set. For this campaign, measurements of organic carbon (OC), elemental carbon (EC) (Zotter et al., 2014), and the most common ions are available. Finally, we have also analyzed 12 filter samples collected in Paris during summer 2009 and winter 2010, where concomitant online HR-ToF-AMS PM measurements are available (Crippa et al., 2013a, b, c; Freutel et al., 2013).

\subsection{Offline AMS}

\subsubsection{Sample extraction}

Sample fractions $\left(2 \mathrm{~cm}^{2}\right.$ or $1.2 \%$ of the entire filter sample, may be increased for low filter loadings) are collected from each filter sample and extracted in $10 \mathrm{~mL}$ ultrapure water $\left(18.2 \mathrm{M} \Omega \mathrm{cm}\right.$, total organic carbon $(\mathrm{TOC})<5 \mathrm{ppb}, 25^{\circ} \mathrm{C}$ ) by means of an ultrasonic generator for $20 \mathrm{~min}$ at $30^{\circ} \mathrm{C}$. Samples are then briefly vortexed $(1 \mathrm{~min})$, to ensure their homogeneity. The extracts are subsequently filtered with
$0.45 \mu \mathrm{m}$ nylon membrane syringe filters, prior to AMS analysis.

\subsubsection{Offline AMS analysis}

The water extracts are aerosolized using a custom-built nebulizer designed to work with small liquid volumes $(5-15 \mathrm{~mL})$. When passing through the nebulizer nozzle, an air stream is accelerated. Simultaneously, liquid is sucked into the nebulizer. The high velocity air stream breaks up the solution and forms particles. The resulting particles are dried by a silica gel diffusion dryer, and subsequently analyzed by the HRToF-AMS (V-mode). For each sample, spectra are recorded in the range of 12-300 amu, with a collection time for each spectrum of 30-60 s. To reduce memory effects, ultrapure water is nebulized before every sample measurement. This information is used as a system blank. Raw data depicting the measurement procedure are presented in Fig. 1. Field blanks are analyzed using the same procedure as the sample filters, and the retrieved signals are statistically equal to those obtained from the direct nebulization of ultrapure water. During each experiment, the nebulizer air is also filtered and measured with the AMS to remove gas-phase contributions from the mass spectra (Allan et al., 2004).

The HR-ToF-AMS operating principles, calibration procedures, and analysis protocols are described in detail elsewhere (DeCarlo et al., 2006). The instrument provides quantitative mass spectra of non-refractory $\mathrm{PM}_{1}$ (vacuum aerodynamic diameter $\left.\left(D_{\mathrm{va}}\right) 60-600 \mathrm{~nm}\right)$ components, at $600^{\circ} \mathrm{C}$ and $10^{-7}$ Torr $\left(1.3 \times 10^{-5} \mathrm{~Pa}\right)$. These include organic aerosol and ammonium nitrate and sulfate. Data are analyzed using high-resolution analysis fitting procedures, Squirrel v1.52L (SeQUential Igor data RetRiEvaL) and Pika v1.10C (Peak Integration by Key Analysis, D. Sueper), in the IGOR Pro software package (Wavemetrics, Inc., Portland, OR, USA).

\subsection{Other chemical analysis}

Cations (e.g., $\mathrm{K}^{+}, \mathrm{Na}^{+}, \mathrm{Mg}^{2+}, \mathrm{Ca}^{2+}, \mathrm{NH}_{4}^{+}$) and anions (e.g., $\mathrm{SO}_{4}^{2-}, \mathrm{NO}_{3}^{-}, \mathrm{Cl}^{-}$) were analyzed using an ion chromatographic system (850 Professional, Metrohm, Switzerland) equipped with a Metrosep C4 cation column and a Metrosep A anion column, respectively. For this analysis, $1 \mathrm{~cm}^{2}$ filter fractions were extracted in $15 \mathrm{~mL}$ ultrapure water $(18.2 \mathrm{M} \Omega \mathrm{cm})$. Filters $\left(1.5 \mathrm{~cm}^{2}\right)$ were also analyzed for EC and OC content by a thermo-optical transmission method on a Sunset OC/EC analyzer (Birch and Cary, 1996), following the EUSAAR-2 thermal-optical transmission protocol (Cavalli et al., 2010). Replicate analysis shows a good analytical precision with relative standard deviations of 7.7, 14.8, and $8.1 \%$ for OC, EC, and TC (total carbon), respectively (Zotter et al., 2014). The water-soluble organic carbon (WSOC) estimates from the offline AMS analyses are compared to WSOC measured using a standard method. Following this method, filter samples are extracted in ultrapure water, they 

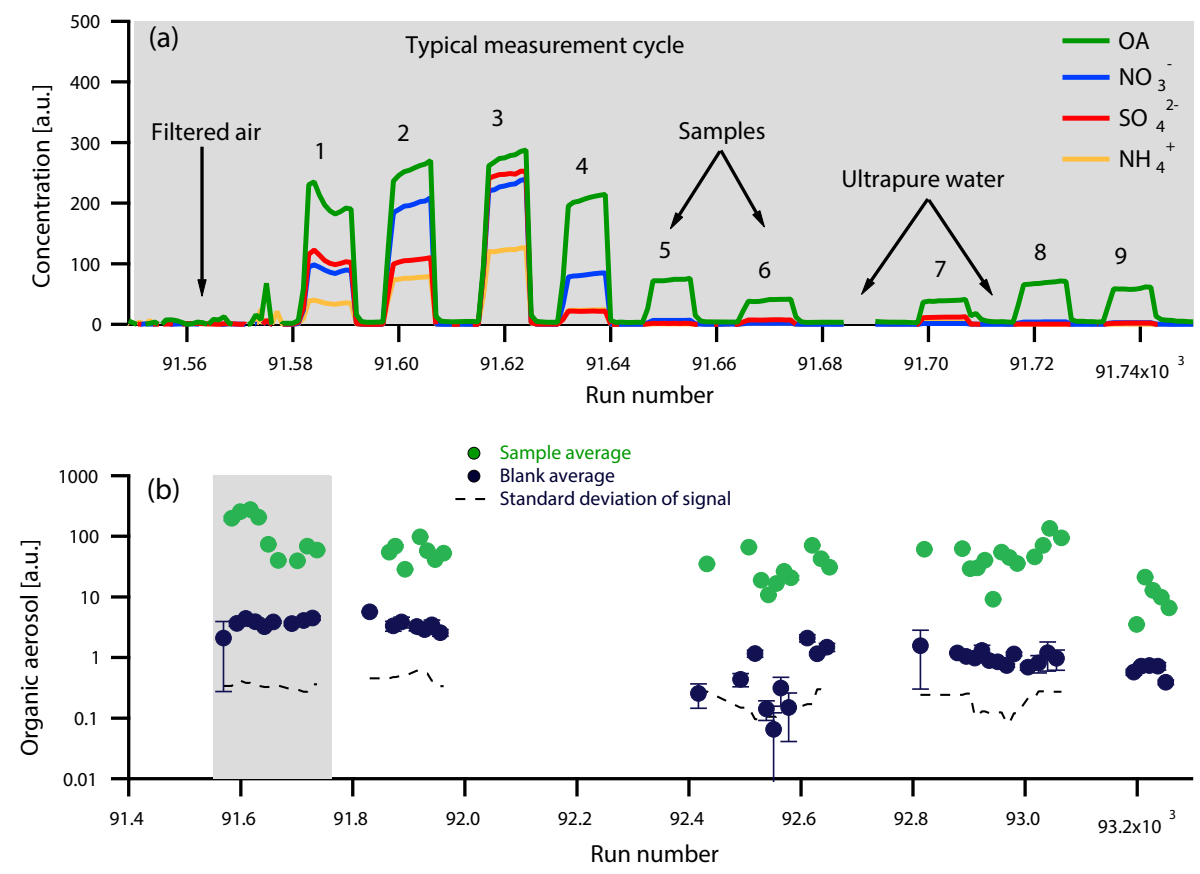

Figure 1. Data recorded with HR-ToF-AMS of filter samples collected in Zurich (2011-2012). Data from a typical measurement cycle are underlaid in gray. (a) Raw signals obtained for organic aerosol (OA, green), nitrate $\left(\mathrm{NO}_{3}^{-}\right.$, blue), sulfate $\left(\mathrm{SO}_{4}^{2-}\right.$, red), and ammonium $\left(\mathrm{NH}_{4}^{+}\right.$, orange), where AMS filter air as well as blank and sample measurements are indicated. (b) OA average signal for samples and blanks (logarithmic scale), blank correction curve and the noise (smoothed standard deviation of the blank) associated with the signal of different species used for the calculation of errors. On the $y$ axes, a.u. denotes arbitrary units.

are gently shaken for $24 \mathrm{~h}$, and the extracts are subsequently analyzed with a TOC analyzer. The bulk of these offline measurements are used as reference methods to assess the offline AMS approach.

\subsection{PMF using ME-2}

The ability of the offline AMS analysis to characterize the organic aerosol sources compared with other online techniques (i.e., ACSM) is evaluated by analyzing the obtained mass spectra from online and offline measurements using positive matrix factorization (PMF, Paatero and Tapper, 1994) for the case of the yearly cycle from Zurich (2011-2012). PMF is a bilinear unmixing receptor model used to describe measurements (in this case AMS or ACSM organic mass spectra time series) as a linear combination of static factor profiles and their time-dependent source contributions, as expressed in Eq. (1):

$x_{i j}=\sum_{k=1}^{p}\left(g_{i k} \times f_{k j}\right)+e_{i j}$.

Here $x_{i j}, f_{k j}, g_{i k}$, and $e_{i j}$ are matrix elements of the measurement, factor profile, factor time series, and residual matrices, respectively. The subscript $j$ corresponds to a measured ion or $m / z, i$ corresponds to a measured time stamp, and $k$ to a discrete factor. The user determines the number of factors, $p$, returned by the PMF algorithm. PMF requires non-negative entries for $f_{k j}$ and $g_{i k}$, suitable for environmental measurements such as OA mass concentrations. The PMF algorithm solves Eq. (1) by iteratively minimizing the object function $Q$, defined as

$Q=\sum_{i} \sum_{j}\left(\frac{e_{i j}}{\sigma_{i j}}\right)^{2}$

where $\sigma_{i j}$ are the elements of the error matrix (measurement uncertainties), which together with $x_{i j}$ and $p$ are provided as model inputs. Measurement uncertainties considered in the error matrix include electronic noise, ion-to-ion variability at the detector, and ion counting statistics (Allan et al., 2003). For offline AMS analyses, both sample and blank uncertainties are incorporated. Following the recommendation of Paatero and Hopke (2009), variables with low signal-to-noise $(\mathrm{SNR}<0.2)$ are removed (no variables affected), whereas "weak" variables $(0.2<\mathrm{SNR}<2)$ are downweighted by a factor of 3 (26 variables in the PMF input affected). Further, 19 variables were not considered in PMF because they were not present in the reference spectra used.

In this study, PMF is solved using the multi-linear engine (ME-2) (algorithm Paatero (1999) and references therein), with the toolkit Source Finder (SoFi version 4.7, Canonaco et al., 2013) for IGOR Pro (Wavemetrics, Inc., Portland, OR, USA) employed as a front end for the model. PMF was op- 
erated using the robust outlier treatment mode, in which outliers were dynamically downweighted. Most published analyses using PMF are limited in their ability to explore rotational ambiguity in the solution space, which is typically accessible only in a single, random dimension (Zhang et al., 2011). As a consequence, these analyses do not guarantee the access to environmentally optimal solutions. In contrast, the ME-2 implementation of PMF allows efficient exploration of the entire solution space, including approximate matrix rotations. In the present study, the solutions were directed towards environmentally meaningful rotations by constraining the elements of one or more profiles in the factor profiles matrix $\left(f_{k j}\right)$ to a predetermined range defined by a center value $\left(f_{k j}^{\prime}\right)$ and a scalar defining the width of range $(a)$, such that the returned profile satisfies $f_{k j}=f_{k j}^{\prime} \pm a \times f_{k j}^{\prime}$. This approach has previously been utilized for AMS data sets to separate distinct sources with correlated mass spectra profiles or time series (Lanz et al., 2008; Crippa et al., 2014) and shown to provide improved factor separation compared to conventional PMF (Canonaco et al., 2013).

In the case of the offline AMS, the HR data matrices were arranged as follows: in the measurement matrix, each filter sample is represented by on average eight high-resolution mass spectra (see description above and Fig. 1), corrected for the corresponding average blank measured before the sample. Each mass spectrum is composed of $154 \mathrm{HR}$ ions $(m / z$ 12-96). 41 samples were considered in this analysis (total of 41 time points and matrix total dimension of $334 \times 154=51436$ ). The corresponding error matrix has the same dimensions. The elements of the error matrix, $\sigma_{i j}$, include the uncertainties related to the AMS measurements as discussed above (computed according to Allan et al., 2003; Ulbrich et al., 2009), denoted by $\delta_{i j}$, added in quadrature to the variability of the preceding blank $\beta_{i j}$, which includes the AMS measurement precision but also accounts for possible drifts in the nebulization:

$\sigma_{i j}=\sqrt{\delta_{i j}^{2}+\beta_{i j}^{2}}$.

In order to allow comparisons with external data, the offline AMS data and error matrices are converted to ambient concentrations. The contribution of $\delta_{i j}$ and $\beta_{i j}$ to $\sigma_{i j}$ depends on the ion in question, but in general $\delta_{i j}$ dominates $(98 \%$, first and third quartiles of 89 and $100 \%$ ). Since the measured data points are not averaged prior to the ME-2 analysis, but rather used individually, their variability is not included in the error matrix, but instead directly reflected in the results. This also provides a metric for the mathematical stability of the ME-2 solution and thus a part of the uncertainties of the source apportionment results.

In order to assess the performance of offline AMS data in source apportionment we compare the obtained results to source apportionment results using online ACSM data. For an ideal offline/online comparison, the online data set should resemble the offline data set as closely as possible. However, the low mass resolution of the ACSM spectra prevents satisfactory factor resolution, when using $24 \mathrm{~h}$ averages of ACSM data for the selected days. Moreover, running ME-2 on the selected days for the entire year (retaining $30 \mathrm{~min}$ time resolution) results in biases between winter and summer residual distributions, which was not the case for the offline data. That is, the model tends to explain the diurnal variation of the online ACSM data, rather than seasonal differences. For these reasons, a rolling window ME-2 approach was developed to perform source apportionment analysis on the yearly online UMR ACSM data (Zurich 2011-2012) (Canonaco et al., 2016). The approach can be described as a controlled bootstrap technique applied to sorted data, which would help represent summer and winter data and provide an estimate of the uncertainties (Paatero et al., 2014). In this approach, a rolling window is capable of capturing seasonal variations in the aerosol factors and/or variations driven by meteorology. Within a window, which is considerably shorter than the yearly data set, the ME- 2 model is applied, allowing the factors to adapt to the measured data. A rolling window corresponds to 4 weeks of measurements and rolls over the whole set of data with a 1 day time step. The PMF window was rolled over the temperature-sorted Zurich data (by daily average temperature). By sorting the data with respect to temperature, days with similar conditions in terms of SOA formation and dominant primary sources (e.g., BBOA at lower temperature) are grouped together. For every window the solution was optimized using criteria based on correlations between the time series and the diurnal cycles of the factors and those of the markers. This novel approach was compared to classical source apportionment results for the winter part of this data set presented in Canonaco et al. (2013). The rolling window solution presents an improved representation of OOA $\left(r^{2}\right.$ with $\mathrm{NH}_{4}^{+} 0.69$ vs. on average 0.53 for the PMF solution in Canonaco et al., 2013) for the overlapping period, which is consistent with the variable character of OOA. The correlation of HOA and BBOA with their respective markers is comparable to Canonaco et al. (2013). For the reasons described above and with the lack of standard techniques to apply PMF to yearly organic mass spectral data, the rolling window source apportionment results are chosen as reference.

\section{Results and discussion}

\subsection{Signal-to-noise, quantification and detection limits}

Figure 1a shows a typical time pattern of $\mathrm{OA}, \mathrm{NO}_{3}^{-}, \mathrm{SO}_{4}^{2-}$, and $\mathrm{NH}_{4}^{+}$from offline AMS measurements. The signal intensity of offline AMS measurements can be expressed in $\mu \mathrm{g} \mathrm{m}^{-3}$ (of nebulized aerosol), but for simplicity we denote this as arbitrary units (a. u.) to avoid confusion with concentrations in ambient air $\left(\mu \mathrm{g} \mathrm{m}^{-3}\right)$. This conversion between AMS signals and real concentrations is explained below. The intensity of $\mathrm{OA}$ is typically $1-2$ orders of magnitude higher 


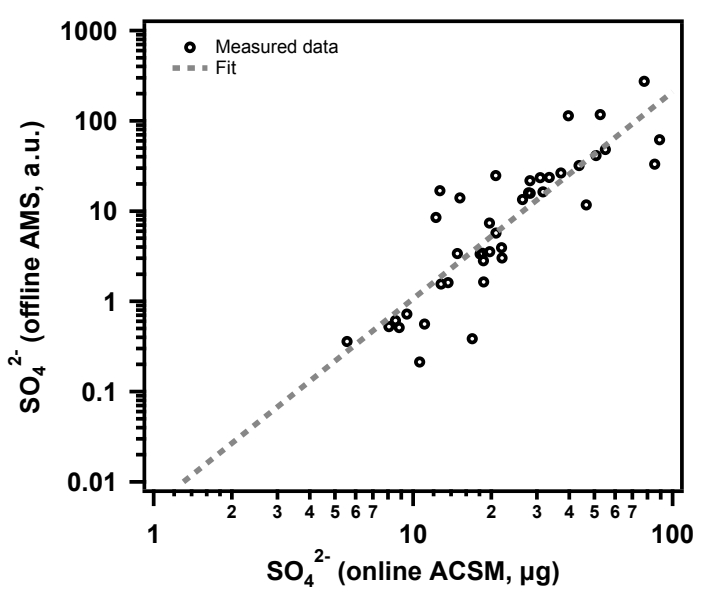

Figure 2. Offline AMS $\mathrm{SO}_{4}^{2-}$ blank corrected concentrations compared to theoretical $\mathrm{SO}_{4}^{2-}$ loadings of the filter fractions $(\mu \mathrm{g})$. The theoretical $\mathrm{SO}_{4}^{2-}$ loadings are calculated based on ambient $\mathrm{SO}_{4}^{2-}$ concentrations measured by the ACSM for the Zurich yearly cycle and the volume of air sampled through the analyzed filter fraction. Results are fitted using a power function $(\ln (y)=2.3 \times \ln (x)-5.2)$.

than that of the measurement blanks (see Fig. 1b). The blank offline AMS signal is typically below 2.1 a. u., with interday and intraday variation (standard deviation) of 0.3 and 1.5 a. u., respectively. The nebulization efficiency assessed based on the $\mathrm{SO}_{4}^{2-}$ signal is $3.8 \mathrm{~mL}_{\text {solution }} \mathrm{m}_{\text {air }}^{-3}$ (first and third quartile of 1.2 and $7.3 \mathrm{~mL}_{\text {solution }} \mathrm{m}_{\text {air }}^{-3}$ ). The particles generated with this nebulizer have a mode diameter of $\sim 200 \mathrm{~nm}$ $\left(\mathrm{d} V / \mathrm{d} \log D_{\mathrm{p}}\right)$.

The $\mathrm{SO}_{4}^{2-}$ detected by the offline AMS is related to $\mathrm{SO}_{4}^{2-}$ loadings on the filter area (calculated from ACSM measurements) analyzed by a power relationship (Fig. 2). However, the offline AMS measurements described herein cannot be directly quantified, without external measurements of e.g., OC, due to variability in the nebulization process. Another significant source of uncertainty is the ACSM cutoff $\left(D_{\text {va }} 600 \mathrm{~nm}\right)$.

The detection limit $\left(\mathrm{dl}_{j}\right)$ of species $j$ (e.g., $\mathrm{SO}_{4}^{2-}$ ), in $\mu \mathrm{g}$ on the analyzed filter fraction, is evaluated based on the blank variability of $j$ in comparison to the signal in the sample, $\sigma_{\text {blank, }, j}$. We define $\mathrm{dl}_{j}$ as the mass of $j$ in $\mu$ g required to produce a signal equal to $3 \times \sigma_{\text {blank, } j}$. $\mathrm{dl}_{j}$ is inferred using the existing relationship between blank corrected offline AMS signals, $I_{j}$ in a. u., and the mass concentration of $j, M_{j}$ in $\mu \mathrm{g}$, in the analyzed filter fractions (e.g., Fig. 2). We estimated the detection limits for $\mathrm{OA}$ and $\mathrm{SO}_{4}^{2-}$ as 0.80 and $0.25 \mu \mathrm{g}$ on the analyzed filter area, corresponding to 80 and $25 \mu \mathrm{g} \mathrm{L}^{-1}$, respectively.

\subsection{OA recovery}

The loss of hydrophobic or volatile organic species during sample collection, handling, extraction, and nebulization may significantly hinder the applicability of the offline AMS technique. In the following, the organic aerosol signals are normalized to the sulfate mass, in order to evaluate OA recoveries. This is based on the assumption that sulfate is quantitatively extracted and measured by the AMS, which is expected since sulfate is mostly bonded to ammonium (watersoluble and non-refractory). This is not given at all sites, e.g., in the strong presence of potassium. We also assume that the fractional composition in the size range sampled by both ACSM and filter samples is the same. Accordingly, the comparison of $I_{j}$ and $M_{j}$ both normalized to $\mathrm{SO}_{4}^{2-}$ yields the recovery $R_{j}$ :

$$
R_{j}=\frac{\left(\frac{I_{j}}{I_{\mathrm{SO}_{4}^{2-}}}\right)_{\text {offline }}}{\left(\frac{M_{j}}{M_{\mathrm{SO}_{4}^{2-}}}\right)_{\text {online }}} .
$$

The extraction time does not have a statistically significant effect on $\mathrm{OA} / \mathrm{SO}_{4}^{2-}$ ratios and fingerprints when increasing the extraction time from 20 to $60 \mathrm{~min}$. Likewise, multiple extractions did not significantly enhance the recovery of the particulate compounds as the OA signal from the second extraction was below $8 \%$ of that from the first extraction and only 3 times higher than the blank signal. Therefore, we have concluded that a single extraction step was sufficient in our case to obtain the water-extractable material.

We have evaluated the recovery of the bulk OA $\left(M_{j}\right.$ here representing OA), by comparing the offline AMS OA $/ \mathrm{SO}_{4}^{2-}$ ratios with $\mathrm{OA} / \mathrm{SO}_{4}^{2-}$ from reference measurements using the Sunset OC/EC analyzer and ion chromatography (IC) (described in Sect. 2.3). The recovery of complex mixtures such as ambient OA depends on the water solubility of its numerous compounds. Figure 3 a compares offline AMS and reference measurements for 15 stations in Switzerland where the reference measurements were performed on the same filters (150 $\mathrm{PM}_{10}$ samples, Table 1$)$, using IC and the Sunset $\mathrm{OC} / \mathrm{EC}$ analyzer for $\mathrm{SO}_{4}^{2-}$ and OA measurements, respectively. The latter were calculated by multiplying the Sunset OC/EC analyzer OC with the OM/OC ratios from the HR analysis of the AMS spectra. While we acknowledge that also OM/OC from offline AMS is subjected to errors caused by compound-dependent extraction efficiencies and filter sampling artifacts, such errors do not significantly affect the results and the OM/OC range found here (median of 1.84 , first quartile of 1.80 and third of 1.87) compare well with previously measured online ratios (e.g., 1.80 provided by Favez et al. (2010) for Grenoble, January 2009, 1.66 by Crippa et al. (2013c) for Paris, and 1.6 and 2.0 by Minguillón et al. (2011) for Barcelona and Montseny, respectively). From this, we estimate a median $R_{\text {bulk }}$ of 0.60 (first and third quartiles of 0.49 and 0.80 ), which suggests that the technique can capture a large part of the organic fraction. 

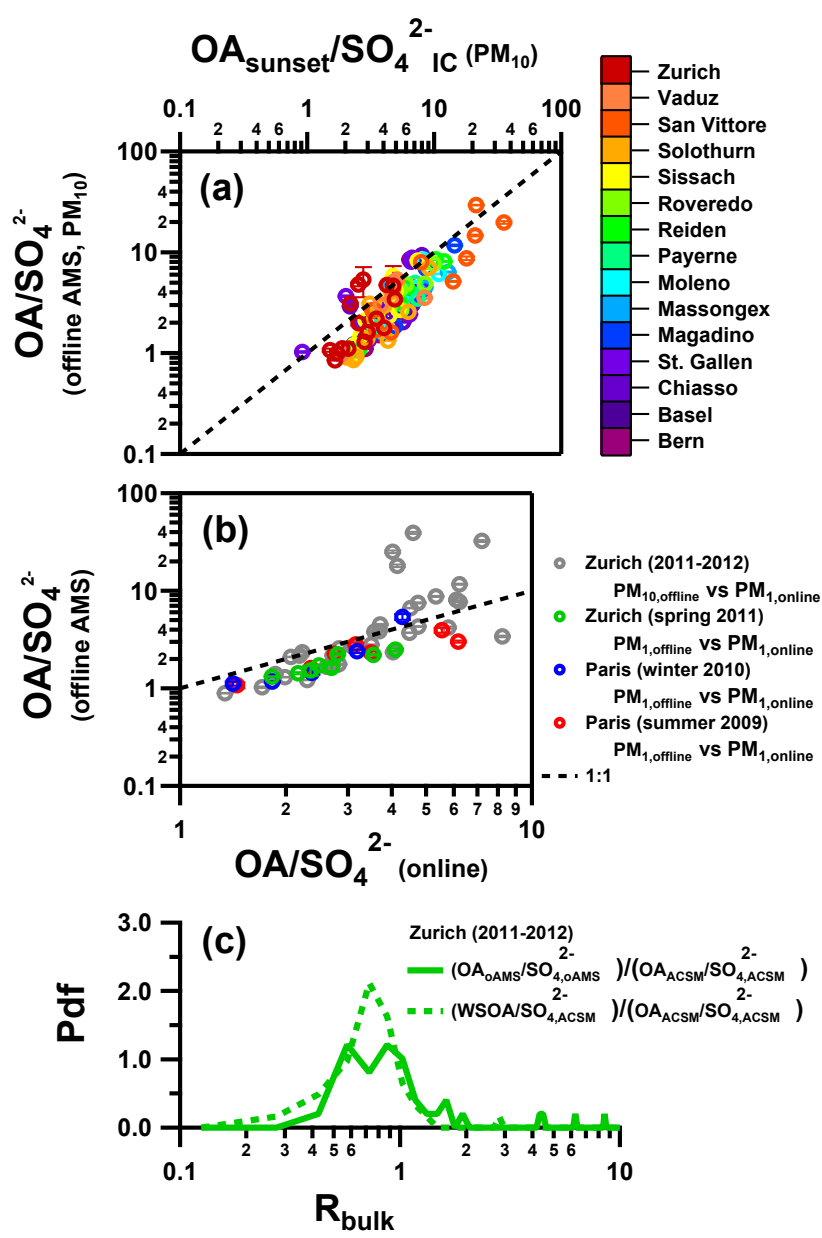

Figure 3. Estimated recoveries of organic compounds based on the comparison of $\mathrm{OA} / \mathrm{SO}_{4}^{2-}$ ratios using the offline AMS method to reference measurements for different days. The error bars represent the variability of the offline $\mathrm{OA} / \mathrm{SO}_{4}^{2-}$ ratio within a sample and were obtained from different runs during the same measurement of the same sample. (a) The reference $\mathrm{OA} / \mathrm{SO}_{4}^{2-}$ ratio is obtained by OC filter measurements (Sunset OC/EC analyzer) scaled to OA using $\mathrm{OM} / \mathrm{OC}$ values from the $\mathrm{HR}$ offline AMS data and $\mathrm{SO}_{4}^{2-}$ from IC. (b) $\mathrm{OA} / \mathrm{SO}_{4}^{2-}$ ratios from online measurements were used as reference values. For both Paris campaigns and the Zurich spring campaign, the online measurements were conducted using HR-ToFAMS and for the yearly cycle in Zurich by a quadrupole ACSM. (c) For Zurich (2011-2012), probability density functions of $R_{\text {bulk }}$ are presented both using the offline AMS measurements as well as using WSOC from the Sunset OC/EC Analyzer (in combination with $\mathrm{OM} / \mathrm{OC}$ ratios from offline AMS).

Similar comparisons between offline AMS results and reference measurements were also performed for other data sets where online AMS data were available (Zurich spring and Paris campaigns). Offline AMS measurements of filter samples collected in Paris (summer 2009 and winter 2010) and Zurich (spring 2011) were compared with online HR-ToFAMS with the same size cutoff $\left(\mathrm{PM}_{1}\right)$ (Fig. 3b). For these

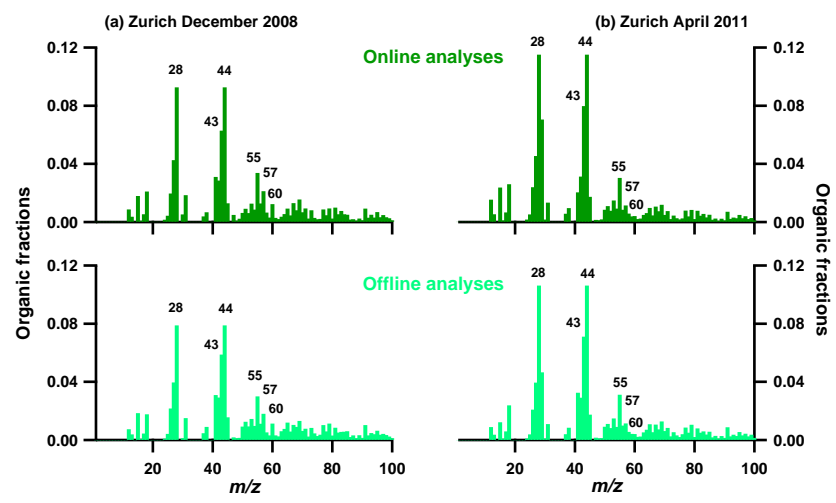

Figure 4. Comparison between $24 \mathrm{~h}$ average online and offline AMS (both $\mathrm{PM}_{2.5}$ ) spectra for winter (a) and spring (b) samples, collected in Zurich. Fragments $(\mathrm{m} / \mathrm{z}$ ) commonly considered as source-specific markers are explicitly labeled with their nominal mass.

data sets, OA recoveries range between 64 and $76 \%$. For Zurich, it should be noted that $\mathrm{PM}_{1}$ filter samples are not available and therefore offline $\mathrm{PM}_{10} \mathrm{HR}-\mathrm{ToF}-\mathrm{AMS}$ measurements are compared to online data from ACSM (yearly cycle) and HR-ToF-AMS equipped with a $\mathrm{PM}_{2.5}$ lens (spring). We show that for both campaigns the overall $R_{\text {bulk }}$ is in the same range as values obtained for the other data sets inspected here, despite the potential contribution of coarse mode OA (median $=0.91$; first and third quartiles of 0.66 and 1.32 , respectively for the yearly cycle and median $=$ 1.05; first and third quartiles of 0.99 and 1.26 , respectively for the spring campaign). This implies that the contribution of the latter is not dominant, consistent with previous measurements at this site, suggesting that the fine particle mass constitutes on average $75 \%$ of the $\mathrm{PM}_{10}$ mass (Putaud et al., 2010). Note that outliers in $R_{\text {bulk }}$ higher than 1 are associated with very low, and therefore highly uncertain sulfate concentrations. For the Zurich yearly cycle campaign (2011-2012), we validated the $R_{\text {bulk }}$ calculation approach adopted here to a more conventional approach for the determination of WSOC (Fig. 3c; water-soluble organic aerosol, $\left.\mathrm{WSOA}=\mathrm{WSOC} \times(\mathrm{OM} / \mathrm{OC})_{\text {offline AMS }}\right)$. We show that both approaches give similar estimates (based on the WSOC median $R_{\text {bulk }}=0.74$ compared to $R_{\text {bulk }}=0.91$ if the calculation is based on the ACSM), suggesting that offline AMS measurements are related to WSOA and that a great part of the organic mass is accessible by the analysis procedure followed here.

\subsection{Mass spectral analysis}

Results above raise the question as to whether the offline AMS analysis maintains the mass spectral signature of the ambient OA. We have addressed this question by comparing online and offline OA mass spectra in Fig. 4, illustrating an example of the results obtained from Zurich win- 

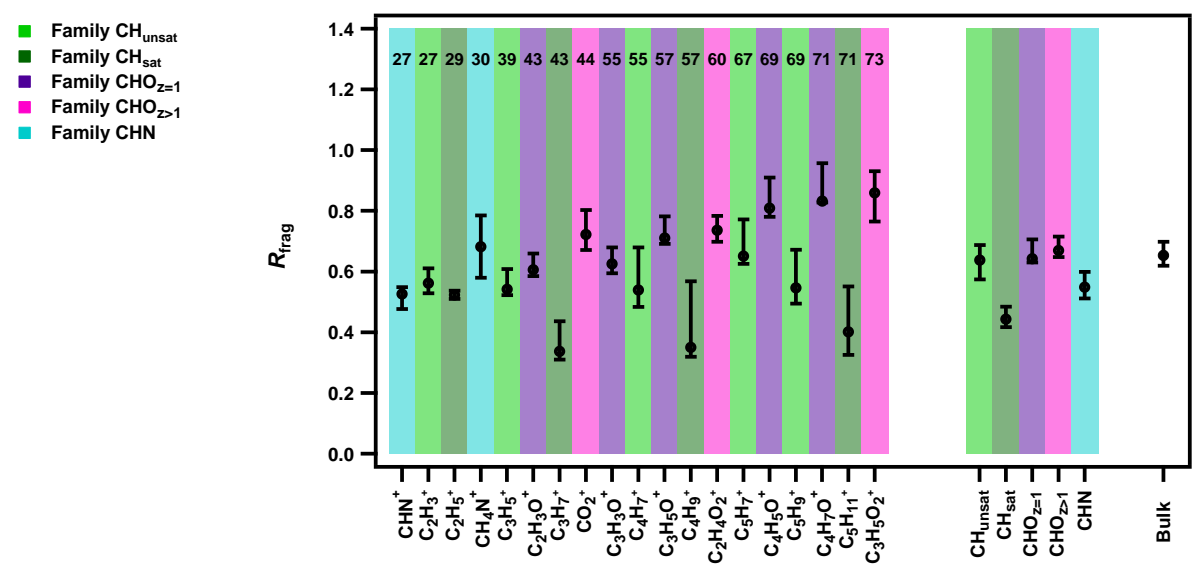

Figure 5. Median recovery of single organic fragments, and chemical families for the Zurich spring campaign (offline vs. online PM 2.5 AMS). The first and third quartiles of the inter-sample variability are shown as error bars. A ratio of 1 indicates a recovery of $100 \%$. The fragments are color-coded with the family $\left(\mathrm{CH}\right.$ (hydrocarbon fragments, split into saturated and unsaturated), $\mathrm{CHO}_{z=1}$ and $\mathrm{CHO}_{z>1}$ (oxygenated fragments), and CHN, nitrogen-containing hydrocarbon fragments). Numbers across the top of the plot indicate the fragments' nominal mass. Families include all respective fragments weighted by their mass contribution.

ter and spring campaigns. Such a comparison implicitly assumes that the mean organic composition across the entire size range collected by the filter (up to $\mathrm{PM}_{10}$ ) is identical to that of the approximately $60-600 \mathrm{~nm}$ particles measured by the online ACSM. Although this assumption will not hold for all conditions, the comparison is nonetheless useful for characterization of the offline AMS technique. The comparison of offline and online spectra shows a high correlation $\left(R^{2}>0.97\right)$ irrespective of the seasonal variation in aerosol composition. More importantly, it can be observed that this method is also able to capture variations in the aerosol fingerprints between the two seasons. For instance, both online and offline methods show higher contributions from BBOAand HOA-related fragments (e.g., $m / z 60,73$, and $m / z$ 55, 57,69 , respectively) for the winter samples and higher contributions from OOA-related $m / z$ values (e.g., $m / z, 43,44$ ) for the spring sample.

HR-ToF-AMS data enable the analysis of individual ions at the same integer $m / z$, which in turn provides better assessment of the recovery of the initial parent organic compounds or ion families. For this analysis, we use Eq. (4) to describe the recovery of individual ions $R_{\text {frag }}$ with $M_{j}$ and $I_{j}$ defined as the concentration of an individual ion $\left(c_{\text {frag }}\right)$. We have grouped the fragments into five different families, based on their heteroatom content and degree of unsaturation, including $\mathrm{N}$-containing hydrocarbon ions $(\mathrm{CHN})$, monooxygenated $\left(\mathrm{CHO}_{z=1}\right)$ and poly-oxygenated $\left(\mathrm{CHO}_{z>1}\right)$ ions and pure hydrocarbons $(\mathrm{CH})$ divided into saturated $\left(\mathrm{CH}_{\text {sat }}\right)$ and unsaturated hydrocarbons $\left(\mathrm{CH}_{\text {unsat }}\right)$.

Figure 5 presents $R_{\text {frag }}$ for the Zurich spring (2011) campaign (see Fig. $3 \mathrm{~b}$, green points for $R_{\text {bulk }}=0.65$ (first and third quartiles of 0.62 and 0.70 ). Results show that highly oxygenated fragments $\left(\mathrm{CHO}_{z>1}\right.$, mainly organic acids) are well recovered, $R_{\mathrm{CHO}_{z>1}}=67 \%$ (first and third quartiles of
65 and $72 \%$ ). This proportion slightly decreases to $64 \%$ (first and third quartiles of 63 and $71 \%$ ) for the $\mathrm{CHO}_{z=1}$ $\left(R_{\mathrm{CHO}_{z=1}}\right)$ family, which could mainly be composed of alcohols, aldehydes, and ketones. In contrast, $R_{\text {frag }}$ for nonoxygenated species are in general lower, i.e., $55 \%$ (first and third quartiles of 51 and $60 \%)$ for the CHN family $\left(R_{\mathrm{CHN}}\right)$, and $61 \%$ (first and third quartiles of 55 and $64 \%$ ) for the $\mathrm{CH}$ family $\left(R_{\mathrm{CH}}\right)$. Within the $\mathrm{CH}$ family, the saturated hydrocarbon fragments $\left(\mathrm{C}_{n} \mathrm{H}_{2 n+1}^{+}\right)$, which stem at least in part from the fragmentation of hydrophobic normal and branched alkanes (Alfarra et al., 2004), are especially strongly underestimated $\left(R_{\mathrm{C}_{n} \mathrm{H}_{2 n+1}^{+}}=44 \%\right.$, first and third quartiles of 42 and $48 \%)$. Note that a higher variability in the $R_{\text {frag }}$ value is also observed for the $\mathrm{CH}$ fragments, probably due to the variability in the water solubility of their parent molecules. This may lead to higher uncertainties in the source apportionment of hydrocarbon-like OA and even to an underestimation of such sources, using the offline AMS technique, as will be shown below.

\subsection{Source apportionment results}

Differences between offline and online HR-ToF-AMS spectra caused by e.g., compound-dependent recoveries may also influence source apportionment results. Therefore, we assess the ability of the offline AMS in the apportionment of OA sources, by analyzing the offline Zurich yearly data set using ME-2 and comparing the source apportionment results to those obtained by applying ME-2 to online ACSM data.

\subsubsection{ME-2 output evaluation}

A key consideration for PMF analysis is the number of factors selected by the user. As mathematical criteria alone are 


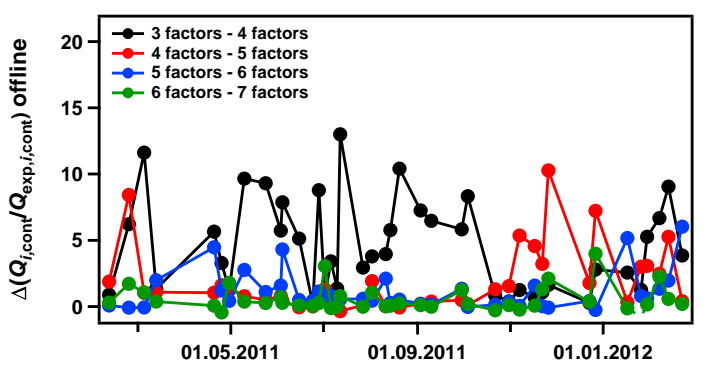

Figure 6. Change in the time-dependent contribution of $Q / Q_{\exp }$ as a function of the number of factors $\Delta\left(Q_{i, \text { cont }} / Q_{\exp , i, \text { cont }}\right)$ for a chosen offline solution (for $a_{\mathrm{HOA}}=0.0$ and $a_{\mathrm{COA}}=0.0$ ).

insufficient for choosing the right number of factors, this selection must be evaluated through comparisons of factor and tracer time series, analysis of the factor mass spectra, and the evolution of the residual time series as a function of the number of resolved factors. As described below, a five-factor solution was selected as the best representation of the offline AMS data. To improve the resolution of the POA sources by the model, literature profiles were used to define the range of acceptable profiles (using the $a$ value approach - Sect. 2.4). SOA factors are not constrained because of the complex dependence of SOA composition on source, atmospheric age, processing mechanisms, and meteorological conditions. This is consistent with the approach of Crippa et al. (2014). After determining the optimal number of factors (and their identity) required for explaining the variability in the data set, we thoroughly assessed the sensitivity of the PMF results to the selection of the $a$ values.

Previous studies at this site have shown the influence of traffic, cooking, biomass burning, and secondary organic aerosol (Lanz et al., 2008; Canonaco et al., 2013). Here, we have constrained HOA and COA (profiles adapted from Mohr et al., 2012) and optimized the solution by investigating different combinations of $a$ values for the constrained factors. In the selected five-factor solution, the non-constrained factors extracted by ME- 2 were related to BBOA, a highly oxygenated (OOA1) and moderately oxygenated (OOA2) organic aerosol; the sum of OOA1 and OOA2 will be henceforth considered as a proxy for secondary organic aerosol (referred to as OOA) which can, though, be mixed with aged primary organic aerosol. These designations are based on the correlation between OOA time series and that of secondary inorganic species (i.e., $\mathrm{SO}_{4}^{2-}$ and $\mathrm{NH}_{4}^{+}$) and the comparison of OOA profile mass spectra with those extracted from previous AMS data sets.

\section{Number of factors}

Figure 6 shows the change in the time-dependent $Q / Q_{\exp }$ when increasing the number of factors for the offline data set $\Delta\left(Q_{i, \text { cont }} / Q_{\text {exp }, i, \text { cont }}\right)$ : contribution to $Q_{i, \text { cont }}$ for the $(p)$ factor solution minus that of the $(p+1)$-factor solution.

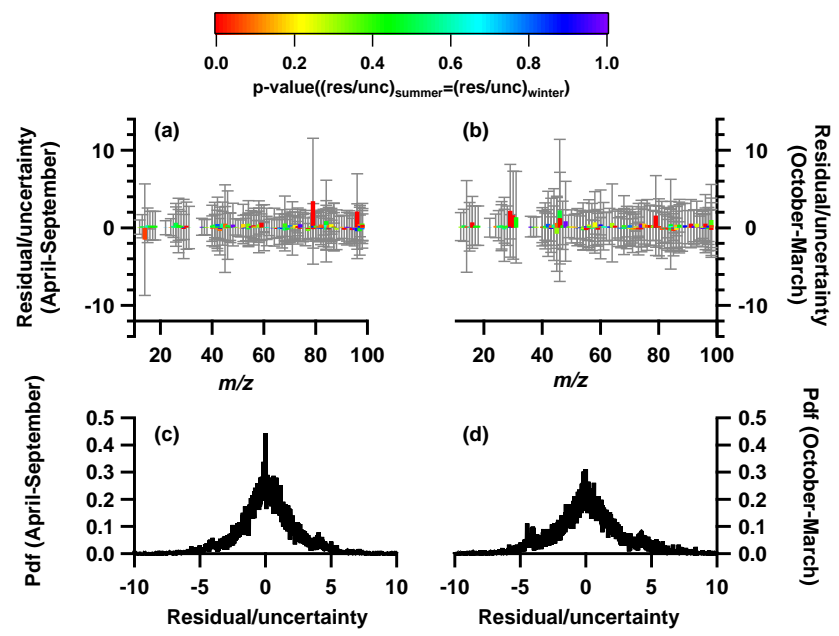

Figure 7. Residuals weighted with the uncertainty (residuals/uncertainty) of the offline solutions for the periods AprilSeptember and October-March (example shown for one chosen solution, $\left.a_{\mathrm{HOA}}=0.0 ; a_{\mathrm{COA}}=0.0\right)$. Panels $(\mathbf{a}, \mathbf{b})$ show residuals as a function of $\mathrm{m} / \mathrm{z}$ averaged over the whole periods color-coded with the probability that the residuals for April-September are the same as for October-March (Wilcoxon-Mann-Whitney test). Panels (c, d) shown the probability distribution function (pdf) of $R / U$ during the same periods.

A significant decrease in $\Delta\left(Q_{i, \text { cont }} / Q_{\exp , i, \text { cont }}\right)$ signifies that structure in the residuals disappeared with the additional factor. Removed structure is evident up to five factors. This behavior indicates that while the ME-2 solution is clearly enhanced when increasing the number of factors to five, addition of further factors does not improve the model description of the input data. For this solution, there is no statistically significant difference in the residual distributions of most variables between winter and summer (Fig. 7), indicating that the modeled profiles represent the sources over the entire year well. Lower order solutions (three and four factors) show one or two OOA factors besides the constrained HOA and COA. Higher order solutions were explored but yielded additional OOA factors, which could not be clearly attributed to a distinct source or process. Given this lack of improvement in $\Delta\left(Q_{i, \text { cont }} / Q_{\text {exp }, i, \text { cont }}\right)$ and in the understanding of aerosol sources and formation processes, and the absence of external tracers supporting the additional OOAs in the high order solutions, the five-factor solution was considered as being optimal. Furthermore, we consider only the sum of OOAs to facilitate the inter-method comparison (as explained below). Note that PMF model uncertainties, i.e., imperfect mathematical unmixing of sources, propagate into this comparison. This setting allows a direct comparison between the offline and online methodologies, as the same set of factors are obtained. 
(a) overall

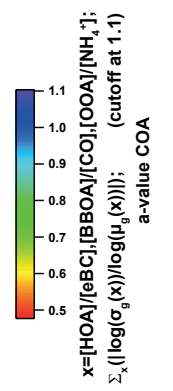

(c)

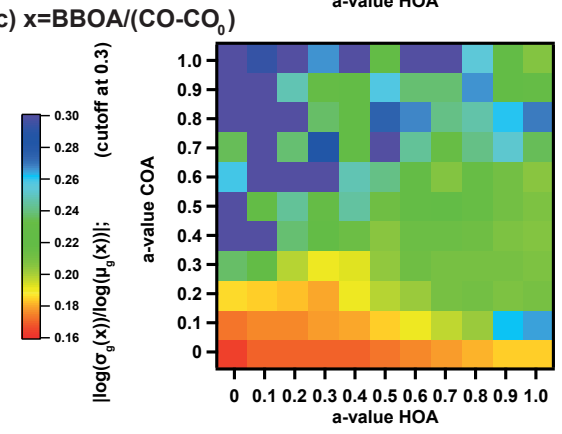

(b) $\mathrm{x}=\mathrm{HOA} / \mathrm{eBC}$

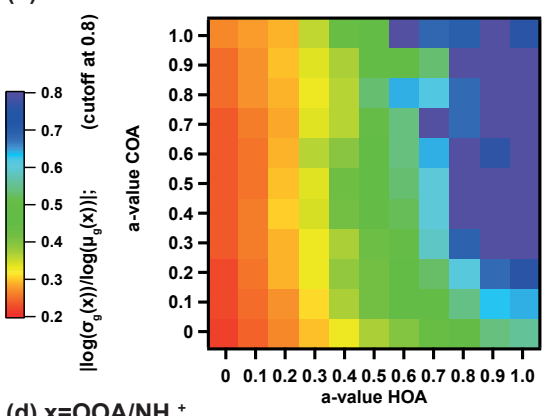

(d) $\mathrm{x}=\mathrm{OOA} / \mathrm{NH}^{+}$

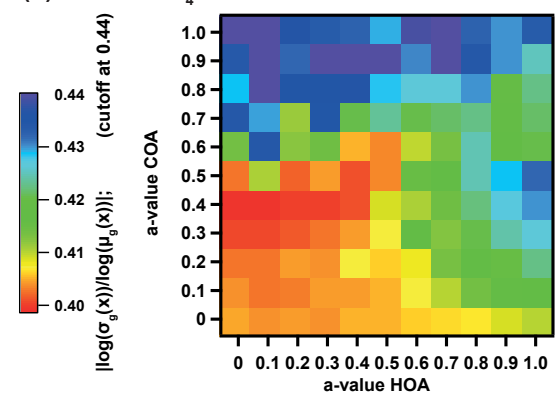

Figure 8. Relative width of the distributions $\left(c_{j} / c_{\text {marker }}\right)$ displayed as a function of $a_{\mathrm{HOA}}$ and $a_{\mathrm{COA}}$. Panel (a) shows the sum of the criteria for HOA, BBOA, and OOA being the sum of OOA1 and OOA2. (The chosen solutions are pointed out in the white area.) Panels (b-d) show the individual criteria as a function of the $a$ values of $\mathrm{HOA}$ and $\mathrm{COA} a_{\mathrm{HOA}}, a_{\mathrm{COA}}$.

\section{$a$ value optimization}

The $a$ values are independently varied for all constrained factors within a wide range ( $a$ values from 0 to 1 with a step size of 0.1) for offline data in order to find an optimal solution. Amongst the different solutions obtained, we selected those with factor time series with the strongest correlation with those of the corresponding tracers. The $a$ value combinations of the chosen solution are specific for the data set used herein and the selected reference profiles used, i.e., they may not be directly applicable to other cases.

For this selection, the approach described above is adopted for the offline data (illustrated in Fig. 8). For each set of $a$ values selected as ME-2 input parameters (two $a$ values to constrain HOA and COA) five-factor time series are first generated by ME-2. The ratios between factor and marker time series are then displayed as probability density functions (pdf). The width of this distribution is used as a quality criterion, since the narrower it is, the closer the linear relation of the factor is to the marker. Here, eBC, $\mathrm{CO}$, and $\mathrm{NH}_{4}^{+}$are used as markers for HOA, BBOA, and OOA, respectively. For COA, no specific marker has yet been identified and studies presenting online data validate this factor using the daily pattern of its concentration, which typically peaks at lunch- and dinner-time (e.g. Crippa et al., 2014). For $24 \mathrm{~h}$ integrated filter data, this diagnostic cannot be used and therefore the optimization of COA separation by ME2 is not used as a quality criterion. In practice, the solution with the narrowest factor-to-marker distributions is de- fined as the best solution with respect to its interpretability in the environment. For the other factors, we have examined the variability in the ratio, $x$, between factor and corresponding marker: $x=\left(\frac{\mathrm{HOA}}{\mathrm{eBC}}\right) ;\left(\frac{\mathrm{BBOA}}{\mathrm{CO}-\mathrm{CO}_{0}}\right) ;\left(\frac{\mathrm{OOA}}{\mathrm{NH}_{4}^{+}}\right) \cdot \mathrm{CO}_{0}$ is the background concentration, which is estimated to be $100 \mathrm{ppb}$. This is both in agreement with measurements at this site and also literature presenting measurements of background air masses (e.g. Griffiths et al., 2014, for Jungfraujoch). In practice, the best solution is obtained by minimizing the sum of the ratios of the logarithmic geometric standard deviations $\left(\sigma_{\mathrm{g}}\right)$ to the logarithmic geometric averages $\left(\mu_{\mathrm{g}}\right)$ of $\left.x\left(\sum_{x} \mid \frac{\log \left(\sigma_{\mathrm{g}}(x)\right)}{\log \left(\mu_{\mathrm{g}}(x)\right)}\right)\right)$. Besides using eBC as an HOA marker, the quality of the solution was also checked using $\mathrm{eBC}_{\mathrm{tr}}$. For both markers, the same $a$ value combination was considered best according the overall criterion. All solutions, for which none of the single distributions showed a different relative variance than the best solution, were also accepted (this comparison was performed using an $F$ test). Note that the determination of the $a$ value ranges resulting in the most satisfactory solutions for the offline data set is performed independently from the online measurements. The comparison between source apportionment from offline and online data sets provides, therefore, a direct measure of the ability of the offline AMS technique to resolve aerosol sources and formation processes. Systematically stepping through the multi-dimensional $a$ value space, as opposed to most published analyses using one-dimensional $a$-value-based ME-2 


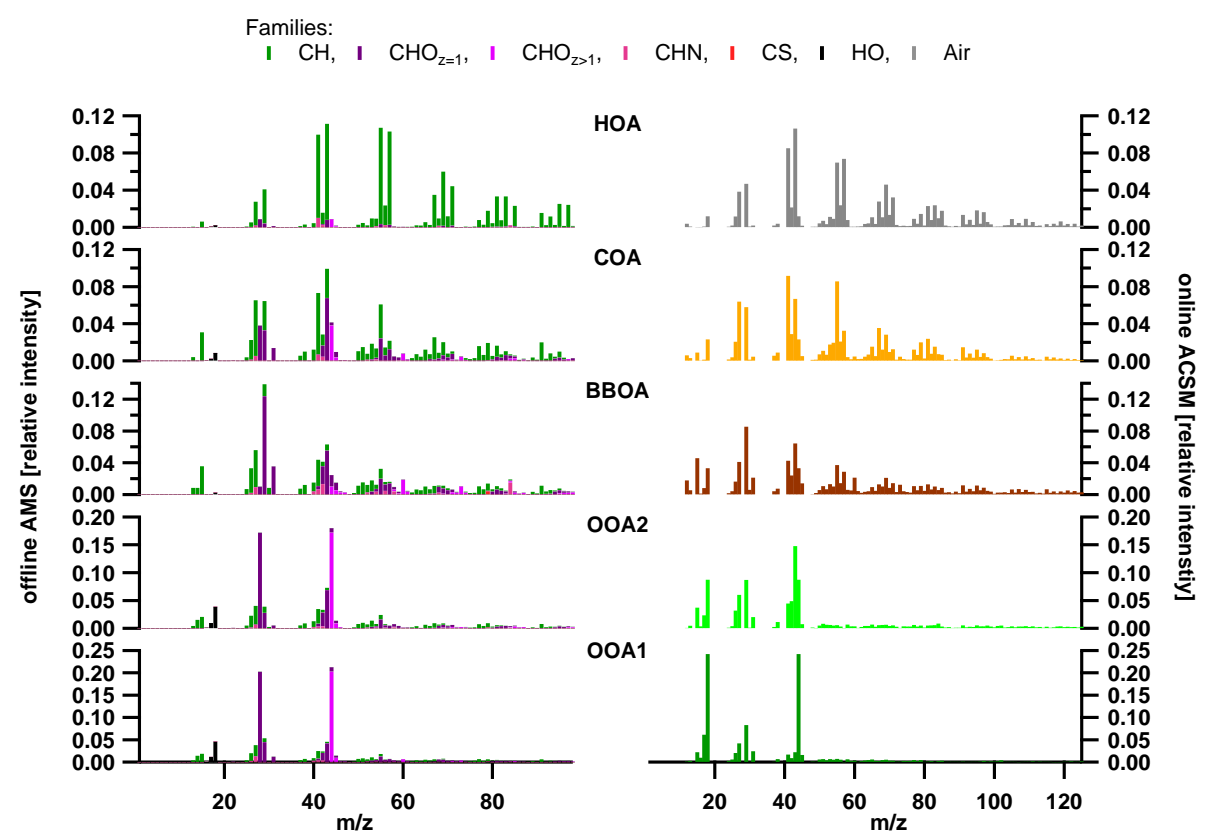

Figure 9. Comparison of overall factor profiles obtained for the chosen solutions both from the offline (left, for HOA and COA, spectra from Mohr et al. (2012) were used as reference) and the retrieved factor profiles from the online source apportionment (right).

or PMF, offers a more effective and objective exploration of the solution space. Environmentally reasonable factors are obtained by selecting the subset of solutions that optimizes factor-to-marker relationships.

The chosen offline solutions lie in general in a part of the solution space with low $a$ values for HOA and COA (the single chosen $a$ value combinations are shown as white boxes in Fig. 8a). The relative variability of the signatures of the constrained factors among the different accepted solutions for the offline source apportionment is below 6 and $3 \%$ for HOA and COA, respectively. Note that this is an incomplete exploration of the rotational ambiguity and thus does not describe the complete model uncertainty.

\section{Online ACSM solution}

Like the offline solution, the online ACSM solution yielded a five-factor solution representing HOA (constrained using the profile reported by Crippa et al., 2013b), COA (constrained using the profile reported by Crippa et al., 2013b), BBOA (constrained using the profile reported by $\mathrm{Ng}$ et al., 2011a), SV-OOA, and LV-OOA. In contrast to the offline solution, ME-2 could not extract BBOA independently; thus this factor was constrained as suggested by Crippa et al. (2014).

Comparing the offline to online PMF source apportionment results obtained with the approaches described earlier has the obvious drawback that we compare OOA factors extracted in winter-only or summer-only (online) vs. combined winter and summer (offline). However, this is mitigated by two factors. First, the discrimination between OOAs for the offline solution is largely driven by seasonal differences (average relative contributions: in winter OOA2 9\%, OOA1 $91 \%$ and in summer $87,13 \%$, respectively), indicating only small biases in the composition. Second, the residuals for both winter and summer are normally distributed and centered around zero (Fig. 7), indicating negligible seasonally dependent bias in the apportioned mass. Therefore, while this comparison method may contribute somewhat to the overall uncertainties, it is unlikely to significantly affect the conclusions or values reported below.

\section{Factor profiles}

The averages of factor profiles of the selected ME-2 online and offline solutions are presented in Fig. 9. Apart from the good correlations between factors and external markers time series used as an acceptance criteria, our results show that the factors retrieved by ME-2 exhibit spectral profiles are consistent with previous studies. The BBOA profile extracted from the offline data set closely resembles those reported in the literature for other locations (Crippa et al., 2013b), characterized by the contribution of oxygenated fragments at $\mathrm{m} / \mathrm{z}$ $29\left(\mathrm{CHO}^{+}\right), 60\left(\mathrm{C}_{2} \mathrm{H}_{4} \mathrm{O}_{2}^{+}\right)$, and $73\left(\mathrm{C}_{3} \mathrm{H}_{5} \mathrm{O}_{2}^{+}\right)$, from fragmentation of anhydrous sugars (Ng et al., 2011a). The OOA mass spectra retrieved by ME-2 for both online and offline data sets is characterized by a typical fingerprint, dominated by oxygenated fragments at $m / z, 43\left(\mathrm{C}_{2} \mathrm{H}_{3} \mathrm{O}^{+}\right)$and 44 $\left(\mathrm{CO}_{2}^{+}\right)$characteristic of secondary compounds. The consistency of these spectral profiles with previously reported pro- 
files from online measurements provides additional support to the source apportionment results presented here.

\subsubsection{Recoveries of different OA categories (HOA, COA, BBOA, OOA)}

While results above show that the bulk OA recovery lies between 60 and $91 \%$ (Sect. 3.2), for the current analysis we assess the recovery of the different factors as representative of ambient compound classes from various sources/processes determined by ME-2. This is based on the comparison between online and offline source apportionment results. However, for this comparison, the approach presented in Eq. (4) cannot be adopted because of the noisy data and/or low sulfate content during periods critical for recovery determination of a specific factor. We therefore perform a selfconsistent calculation of factor-dependent recoveries, which, when applied to the offline data, yield (1) fractional composition consistent with online measurements, and (2) calculated bulk recovery consistent with the measured bulk recovery using WSOA measurements. The implementation is described below (Eq. 5). Let $i$ denote the time index and $k$ the factor index. We define the time-dependent recovery of a factor $k$ $\left(R_{i, k}\right)$ as the time-dependent ratio of the contribution of this factor in the offline $\left(\right.$ off $\left._{i, k}\right)$ and in the online $\left(\mathrm{on}_{i, k}\right)$ solution multiplied by the time-dependent bulk recovery of WSOA, $R_{i, \mathrm{WSOA}}$ (Eq. 5):

$R_{i, k}=R_{i, \mathrm{WSOA}} \times \frac{\text { off }_{i, k}}{\mathrm{on}_{i, k}}$.

Finally, $R_{k}$, the median of $R_{i, k}$ over time, is computed.

$R_{k}$ reflects not only the bias caused by the water extraction but also filter sampling/storage effects and differences between the individual ME-2 solutions. The uncertainty of $R_{k}$ depends both on the uncertainty related to the single offline solution point in time as well as on their spread in comparison to the online solution. The first can be quantified by assessing the model error for the offline and online using the variability of the solution for different model runs. The offline approach adopted here, including several measurements of the same sample in ME-2 (in general eight spectra, called repeats, per sample), enables assessing the performance of the ME-2 solution for different samples and different factors. For this reason, we have repeatedly calculated $R_{k}$ using randomly chosen combinations of (1) different ME-2 offline solutions (selected in Sect. 3.4.1 and reference online solutions (due to the rolling window approach providing individually optimized periods) and (2) different repeats of the offline AMS measurements for the same samples. The result is an ensemble of $R_{k}$ (for each factor 100000 $R_{k}$ values are calculated) displayed in Fig. 10 as probability density functions. The range of these distributions reflects both model and measurement uncertainties. Note that this range does not reflect the variability in time of $R_{i, k}$. The retrieved factor recoveries are consistent with our un-

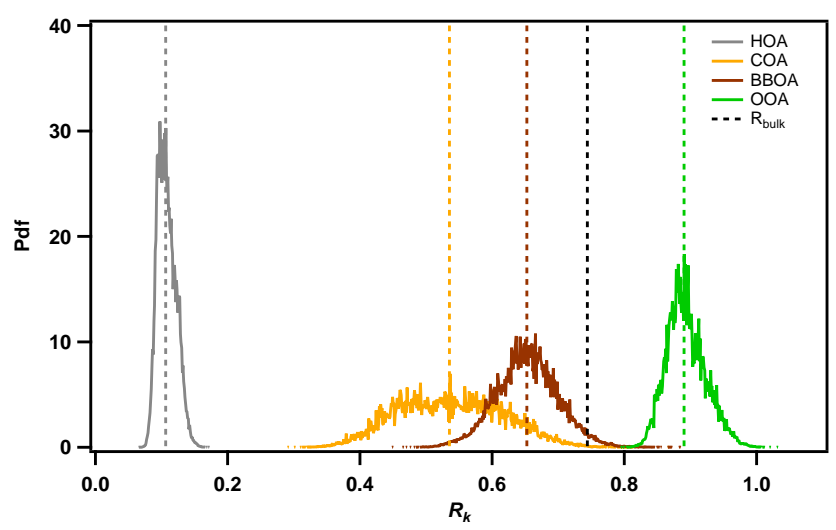

Figure 10. Recoveries $R_{k}$ for HOA, COA, BBOA, and OOA (OOA1 + OOA2) obtained from the intercomparison of source apportionment results of offline AMS to online ACSM data (Zurich 2011-2012). 100000 random combinations of offline and online solutions and randomly chosen offline repeats result in the same amount of time-independent $R_{k}$, which are expressed as probability density functions (pdf).

derstanding of the chemical nature of the different OA components, with primary hydrophobic species less efficiently extracted than secondary oxygenated species. As expected, the most hydrophobic component, HOA, has the lowest recovery with a median $R_{\mathrm{HOA}}$ of $11 \%$ (first and third quartiles of 10 and $12 \%$ ). We note that $R_{\mathrm{HOA}}$ is lower than the $R_{\mathrm{CH} \text {,sat }}$ (see Sect. 3.3), which seems to indicate that these ions can also originate from more hydrophilic molecules than those in traffic emissions. COA appears to be moderately soluble, with $R_{\mathrm{COA}}=54 \%$ (first and third quartiles of 48 and $60 \%$ ). BBOA and OOA species were largely recovered with $R_{\mathrm{BBOA}}=65 \%$ (first and third quartiles of 62 and $68 \%$ ) and $R_{\mathrm{OOA}}=89 \%$ (first and third quartiles of 87 and $91 \%$ ). Uncertainties in $R_{\mathrm{WSOA}}$ are not included in the calculation. Further, online measurements have a lower size cutoff than the offline data $(600 \mathrm{~nm}$ vs. $10 \mu \mathrm{m})$, and large accumulation mode particles are expected to preferentially contain OOA, due to their extended aging. This might provide a positive bias to the OOA $R_{k}$ and a negative bias to $R_{k}$ of the other factors.

\subsubsection{Quantitative comparison of offline and online $\mathrm{OA}$ factors}

We assume that the $R_{k}$ values calculated in the previous section are characteristic properties of the retrieved OA components, i.e., that they can be applied throughout the analyzed offline data sets. This allows us to quantitatively compare the mass concentrations of offline and online OA factors retrieved throughout the year. By applying the $R_{k}$ obtained to the offline data set, the source apportionment results (relative composition) can be corrected. In a second step the results can be scaled to ambient concentrations. Here OA con- 


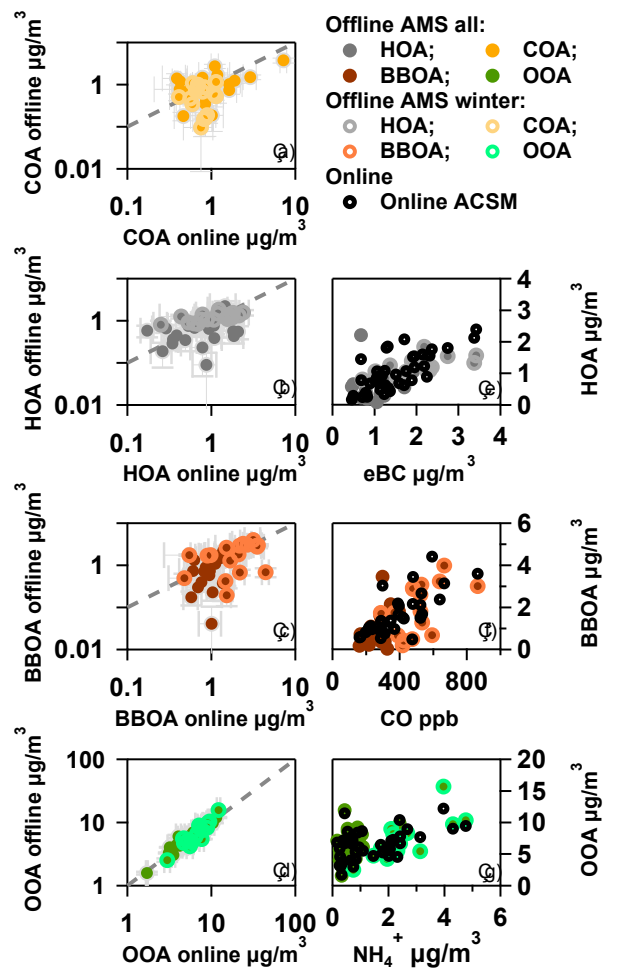

Figure 11. Comparison of factor contributions from separate offline ( $\mathrm{PM}_{10} \mathrm{AMS}$, two constrained factors: HOA, COA) and online $\left(\mathrm{PM}_{1}\right.$ ACSM) source apportionment using ME-2 (traffic (HOA), cooking (COA), biomass burning (BBOA), and oxygenated organic aerosol; OOA $=$ OOA $1+$ OOA2). Factor-specific recoveries $\left(R_{k}\right)$ are applied to the offline contributions. Error bars (in gray) denote the variability between the different ME-2 solutions and for different recorded spectra per sample for offline and for online only the first of the two. Panels (a-d) show scatter plots comparing the absolute contribution of the respective source/OA category for offline AMS and online ACSM measurements. The color code distinguishes all factor contributions (bullets, saturated colors) from winter points (open circle, light colors). The gray dashed line indicates the $1: 1$ line. Panels $(\mathbf{e}-\mathbf{g})$ show the correlation with the respective markers: black symbols represent the absolute contribution of the respective source for the online ACSM measurements and the colored symbols represent the absolute contribution of the same source for the offline AMS measurements.

centrations from the ACSM measurements are used. The $R_{k}$ corrected offline source apportionment results are compared to results from the ACSM analysis and respective marker concentrations (Fig. 11). The displayed error bars reflect the variability of a factor's contribution for one offline sample assessed by the repeats, and also using the different chosen ME-2 solutions provides an estimate of the measurement and (partial) model uncertainties. Overall the variability of the offline factor contributions for an individual sample is $0.1 \mu \mathrm{g} \mathrm{m}^{-3}$. The factors with a lower recovery $R_{k}$ (HOA and COA), reveal also bigger differences between the time series for the offline and online data and thus more scattering. In

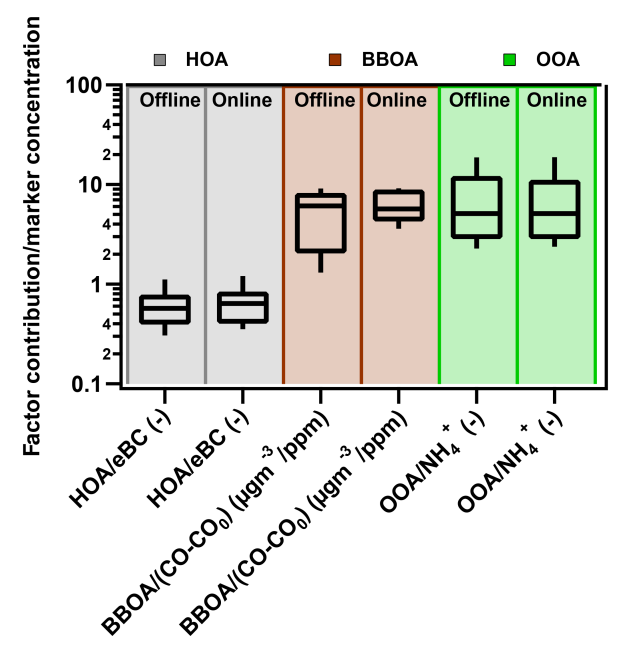

Figure 12. Ranges of ratios of the contribution of different factors to their markers for the offline (corrected with $R_{k}$ ) and online ACSM source apportionment results. Note that OOA is the sum of OOA1 and OOA2.

general, the variability of the offline factor contributions for an individual sample increases when moving away from the $1: 1$ line. This is especially apparent for BBOA, where outliers with low offline concentrations are much more uncertain than the points matching the contribution in the online solution (Fig. 11c, f). All factors but COA (for which no marker is known) show similar relationships with their marker for both offline and online data (Fig. 11e-g).

Figure 12 presents the ratio of factor contributions and their respective marker concentrations for the online and corrected offline solutions. The medians and spreads of the distributions are comparable between offline and online solutions. Only for BBOA is the distribution wider (also seen in Fig. 11). Chirico et al. (2011) and El Haddad et al. (2013) report HOA/EC ratios of 0.4, which is close to the median found in this study $\left(\mathrm{HOA}_{\text {off }} / \mathrm{eBC}=0.57\right.$ (first and third quartiles of 0.42 and 0.74 ), $\mathrm{HOA}_{\text {on }} / \mathrm{eBC}=$ 0.64 ; first and third quartiles of 0.42 and 0.79 ). The ratio $\mathrm{BBOA} /\left(\mathrm{CO}-\mathrm{CO}_{0}\right)$ is 6.1 (first and third quartiles of 2.2 and 7.8) and $5.7 \mu \mathrm{g} \mathrm{m}^{-3} \mathrm{ppm}^{-1}$ (first and third quartiles of 4.5 and 8.4) for offline and online, respectively. However, this ratio has to be considered as a lower limit, as $\mathrm{CO}$ may also be emitted by non-biomass-burning sources (e.g., traffic). While this ratio is significantly lower than values reported for prescribed/open burns (De Gouw and Jimenez, 2009), values found here are within the same range as those measured for modern stoves used in Switzerland (Heringa et al., 2011). Crippa et al. (2014) reported OOA/ $\mathrm{NH}_{4}^{+}$ratios for 25 sites, with an average of 2.0 ( 0.3 for the site with the lowest ratio and 7.3 for the one with the highest). Lanz et al. (2010) reported values of 5.6 and 1.5 for Zurich in July 2005 and January 2006, respectively. The values for Zurich during the period analyzed here are 5.1 (offline, first and third quartiles 
of 3.0 and 11.50) and 5.1 (online, first and third quartiles of 3.0 and 10.5). The examination of these ratios and their comparison with previously reported values provide additional support to the offline AMS methodology and resulting source apportionments. Indeed, the application of this methodology to additional filters from other locations where accompanying online AMS measurements are available may aid the further constraint of the $R_{k}$ estimates presented here.

\section{Conclusions}

In this study, we developed and evaluated an offline method using an HR-ToF-AMS for the characterization of the chemical fingerprints of aerosol collected on filters (Pall quartz filters for the current study). Particulate matter on filters is extracted in water and introduced into the HR-ToF-AMS using a nebulizer. The method was applied to more than 250 filters from different seasons in different environments in Europe. The detection limits depend on the nebulizer and species; for the current setup for OA and $\mathrm{SO}_{4}^{2-}$ they are 80 and $25 \mu \mathrm{g} \mathrm{L}{ }^{-1}$, respectively. External data are needed for quantification. We recommend the use of OC analysis from a Sunset OC/EC analyzer and ion chromatography data for the determination of the inorganic fraction. Estimates of the recovery of bulk OA using different reference measurements show that OA is largely captured (60-91\% depending on the data set). The obtained organic mass spectra are comparable to online HR-ToF-AMS spectra, although hydrocarbons are underestimated. $R_{\text {bulk }}$ also shows a good agreement with the WSOA fraction.

Source apportionment on offline AMS data is conducted with positive matrix factorization, implemented using the ME-2 algorithm. We investigate a set of PMF solutions, for which the different OA components show tight relationships with their respective markers. Thereby, we demonstrate that organic mass spectral data generated using this method are suitable for identifying different OA sources as HOA, COA, BBOA, and OOA. By comparing the results for offline AMS and ACSM data, we retrieved recoveries of the different OA components $\left(R_{k}\right)$ : traffic $\left(R_{\mathrm{HOA}}=0.11\right)$, cooking $\left(R_{\mathrm{COA}}=0.54\right)$, biomass burning $\left(R_{\mathrm{BBOA}}=0.65\right)$, and secondary OA $\left(R_{\mathrm{OOA}}=0.89\right)$. Qualitatively, $R_{k}$ also relates to the water solubility of the respective source, e.g., primary OA related to hydrocarbons (e.g., HOA) shows a low $R_{k}$ caused by its low water solubility. Such $R_{k}$ should be determined at other sites where also additional sources might be important, providing an assessment of site-to-site variability. Nevertheless, these best estimates of $R_{k}$ may be used to correct source apportionment results from offline AMS measurements (as in Huang et al., 2014). When combined with WSOC measurements, one might also be able to assess the applicability of these values at the site in question by comparing overall modelled $R_{\text {bulk }}$ to $R_{\mathrm{WSOA}}$. Even though the offline AMS approach might poorly capture sources exhibiting fast changes, this method broadens the applicability of the AMS to long- term size-segregated $\left(\mathrm{PM}_{1}, \mathrm{PM}_{2.5}, \mathrm{PM}_{10}\right)$ measurements (in contrast to online campaigns of typically 1 month) for extended monitoring networks.

Acknowledgements. This work was supported by the Swiss Federal Office of Environment, inNet Monitoring AG, Ostluft, the country Liechtenstein, the Swiss cantons Basel-Stadt, Basel-Landschaft, Graubünden, Solothurn, Ticino, Thurgau, Valais, the LithuanianSwiss Cooperation Programme "Research and Development" project AEROLIT (Nr. CH-3-ŠMM-01/08), and the IPR-SHOP SNSF starting grant.

Edited by: G. Phillips

\section{References}

Alfarra, M. R., Coe, H., Allan, J. D., Bower, K. N., Boudries, H., Canagaratna, M. R., Jimenez, J. L., Jayne, J. T., Garforth, A. A., Li, S.-M., and Worsnop, D. R.: Characterization of urban and rural organic particulate in the Lower Fraser Valley using two Aerodyne Aerosol Mass Spectrometers, Atmos. Environ., 38, 5745-5758, doi:10.1016/j.atmosenv.2004.01.054, 2004.

Allan, J. D., Jimenez, J. L., Williams, P. I., Alfarra, M. R., Bower, K. N., Jayne, J. T., Coe, H., and Worsnop, D. R.: Quantitative sampling using an aerodyne aerosol mass spectrometer -1 . Techniques of data interpretation and error analysis, J. Geophys. Res.-Atmos., 108, 4090, doi:10.1029/2002JD002358, 2003.

Allan, J. D., Delia, A. E., Coe, H., Bower, K. N., Alfarra, M. R., Jimenez, J. L., Middlebrook, A. M., Drewnick, F., Onasch, T. B., Canagaratna, M. R., Jayne, J. T., and Worsnop, D. R.: A generalised method for the extraction of chemically resolved mass spectra from aerodyne aerosol mass spectrometer data, J. Aerosol Sci., 35, 909-922, doi:10.1016/j.jaerosci.2004.02.007, 2004.

Birch, M. E. and Cary, R. A.: Elemental carbon-based method for monitoring occupational exposures to particulate diesel exhaust, Aerosol Sci. Tech., 25, 221-241, doi:10.1080/02786829608965393, 1996.

Canonaco, F., Crippa, M., Slowik, J. G., Baltensperger, U., and Prévôt, A. S. H.: SoFi, an IGOR-based interface for the efficient use of the generalized multilinear engine (ME-2) for the source apportionment: ME-2 application to aerosol mass spectrometer data, Atmos. Meas. Tech., 6, 3649-3661, doi:10.5194/amt6-3649-2013, 2013.

Canonaco, F., Slowik, J. G., Baltensperger, U., and Prévôt, A. S. H.: Seasonal differences in oxygenated organic aerosol composition: implications for emissions sources and factor analysis, Atmos. Chem. Phys., 15, 6993-7002, doi:10.5194/acp-15-69932015, 2015.

Canonaco, F., Daellenbach, K. R., Crippa, M., ElHaddad, I., Bozzetti, C., Huang, R.-J., Baltensperger, U., Hüglin, C., Herich, H., and Prévôt, A. S. H.: A novel strategy for the source apportionment of long-term ACSM data based on ME-2 with SoFi: Automatic Rolling PMF window (AuRo SoFi), in preparation, 2016.

Cavalli, F., Viana, M., Yttri, K. E., Genberg, J., and Putaud, J.-P.: Toward a standardised thermal-optical protocol for measuring 
atmospheric organic and elemental carbon: the EUSAAR protocol, Atmos. Meas. Tech., 3, 79-89, doi:10.5194/amt-3-79-2010, 2010.

Chirico, R., Prevot, A. S. H., DeCarlo, P. F., Heringa, M. F., Richter, R., Weingartner, E., and Baltensperger, U.: Aerosol and trace gas vehicle emission factors measured in a tunnel using an Aerosol Mass Spectrometer and other online instrumentation, Atmos. Environ., 45, 2182-2192, doi:10.1016/j.atmosenv.2011.01.069, 2011.

Crippa, M., Canonaco, F., Slowik, J. G., El Haddad, I., DeCarlo, P. F., Mohr, C., Heringa, M. F., Chirico, R., Marchand, N., Temime-Roussel, B., Abidi, E., Poulain, L., Wiedensohler, A., Baltensperger, U., and Prévôt, A. S. H.: Primary and secondary organic aerosol origin by combined gas-particle phase source apportionment, Atmos. Chem. Phys., 13, 8411-8426, doi:10.5194/acp-13-8411-2013, 2013a.

Crippa, M., DeCarlo, P. F., Slowik, J. G., Mohr, C., Heringa, M. F., Chirico, R., Poulain, L., Freutel, F., Sciare, J., Cozic, J., Di Marco, C. F., Elsasser, M., Nicolas, J. B., Marchand, N., Abidi, E., Wiedensohler, A., Drewnick, F., Schneider, J., Borrmann, S., Nemitz, E., Zimmermann, R., Jaffrezo, J.-L., Prévôt, A. S. H., and Baltensperger, U.: Wintertime aerosol chemical composition and source apportionment of the organic fraction in the metropolitan area of Paris, Atmos. Chem. Phys., 13, 961-981, doi:10.5194/acp-13-961-2013, 2013b.

Crippa, M., El Haddad, I., Slowik, J. G., DeCarlo, P. F., Mohr, C., Heringa, M. F., Chirico, R., Marchand, N., Sciare, J., Baltensperger, U., and Prevot, A. S. H.: Identification of marine and continental aerosol sources in Paris using high resolution aerosol mass spectrometry, J. Geophys. Res.-Atmos., 118, 1950-1963, doi:10.1002/jgrd.50151, 2013c.

Crippa, M., Canonaco, F., Lanz, V. A., Äijälä, M., Allan, J. D., Carbone, S., Capes, G., Ceburnis, D., Dall'Osto, M., Day, D. A., DeCarlo, P. F., Ehn, M., Eriksson, A., Freney, E., Hildebrandt Ruiz, L., Hillamo, R., Jimenez, J. L., Junninen, H., Kiendler-Scharr, A., Kortelainen, A.-M., Kulmala, M., Laaksonen, A., Mensah, A. A., Mohr, C., Nemitz, E., O'Dowd, C., Ovadnevaite, J., Pandis, S. N., Petäjä, T., Poulain, L., Saarikoski, S., Sellegri, K., Swietlicki, E., Tiitta, P., Worsnop, D. R., Baltensperger, U., and Prévôt, A. S. H.: Organic aerosol components derived from 25 AMS data sets across Europe using a consistent ME-2 based source apportionment approach, Atmos. Chem. Phys., 14, 61596176, doi:10.5194/acp-14-6159-2014, 2014.

DeCarlo, P. F., Kimmel, J. R., Trimborn, A., Northway, M. J., Jayne, J. T., Aiken, A. C., Gonin, M., Fuhrer, K., Horvath, T., Docherty, K. S., Worsnop, D. R., and Jimenez, J. L.: Fielddeployable, high-resolution, time-of-flight aerosol mass spectrometer, Anal. Chem., 78, 8281-8289, doi:10.1021/ac061249n, 2006.

De Gouw, J. and Jimenez, J. L.: organic aerosols in the earth's atmosphere, Environ. Sci. Technol., 43, 7614-7618, doi:10.1021/es9006004, 2009.

El Haddad, I., D’Anna, B., Temime-Roussel, B., Nicolas, M., Boreave, A., Favez, O., Voisin, D., Sciare, J., George, C., Jaffrezo, J.-L., Wortham, H., and Marchand, N.: Towards a better understanding of the origins, chemical composition and aging of oxygenated organic aerosols: case study of a Mediterranean industrialized environment, Marseille, Atmos. Chem. Phys., 13, 78757894, doi::10.5194/acp-13-7875-2013, 2013.
Favez, O., El Haddad, I., Piot, C., Boréave, A., Abidi, E., Marchand, N., Jaffrezo, J.-L., Besombes, J.-L., Personnaz, M.-B., Sciare, J., Wortham, H., George, C., and D'Anna, B.: Inter-comparison of source apportionment models for the estimation of wood burning aerosols during wintertime in an Alpine city (Grenoble, France), Atmos. Chem. Phys., 10, 5295-5314, doi:10.5194/acp-10-52952010, 2010.

Freutel, F., Schneider, J., Drewnick, F., von der Weiden-Reinmüller, S.-L., Crippa, M., Prévôt, A. S. H., Baltensperger, U., Poulain, L., Wiedensohler, A., Sciare, J., Sarda-Estève, R., Burkhart, J. F., Eckhardt, S., Stohl, A., Gros, V., Colomb, A., Michoud, V., Doussin, J. F., Borbon, A., Haeffelin, M., Morille, Y., Beekmann, M., and Borrmann, S.: Aerosol particle measurements at three stationary sites in the megacity of Paris during summer 2009: meteorology and air mass origin dominate aerosol particle composition and size distribution, Atmos. Chem. Phys., 13, 933-959, doi:10.5194/acp-13-933-2013, 2013.

Fröhlich, R., Cubison, M. J., Slowik, J. G., Bukowiecki, N., Prévôt, A. S. H., Baltensperger, U., Schneider, J., Kimmel, J. R., Gonin, M., Rohner, U., Worsnop, D. R., and Jayne, J. T.: The ToF-ACSM: a portable aerosol chemical speciation monitor with TOFMS detection, Atmos. Meas. Tech., 6, 3225-3241, doi:10.5194/amt-6-3225-2013, 2013.

Fröhlich, R., Crenn, V., Setyan, A., Belis, C. A., Canonaco, F., Favez, O., Riffault, V., Slowik, J. G., Aas, W., Aijälä, M., Alastuey, A., Artiñano, B., Bonnaire, N., Bozzetti, C., Bressi, M., Carbone, C., Coz, E., Croteau, P. L., Cubison, M. J., EsserGietl, J. K., Green, D. C., Gros, V., Heikkinen, L., Herrmann, H., Jayne, J. T., Lunder, C. R., Minguillón, M. C., Močnik, G., O’Dowd, C. D., Ovadnevaite, J., Petralia, E., Poulain, L., Priestman, M., Ripoll, A., Sarda-Estève, R., Wiedensohler, A., Baltensperger, U., Sciare, J., and Prévôt, A. S. H.: ACTRIS ACSM intercomparison - Part 2: Intercomparison of ME-2 organic source apportionment results from 15 individual, co-located aerosol mass spectrometers, Atmos. Meas. Tech., 8, 2555-2576, doi:10.5194/amt-8-2555-2015, 2015.

Griffiths, A. D., Conen, F., Weingartner, E., Zimmermann, L., Chambers, S. D., Williams, A. G., and Steinbacher, M.: Surfaceto-mountaintop transport characterised by radon observations at the Jungfraujoch, Atmos. Chem. Phys., 14, 12763-12779, doi:10.5194/acp-14-12763-2014, 2014.

Griggs, D. J. and Noguer, M.: Climate Change 2001: the Scientific Basis, Contribution of working group I to the third assessment report of the Intergovernmental Panel on Climate Change, Weather, 57, 267-269, 2002.

Hansen, A. D. A., Rosen, H., and Novakov, T.: The Aethalometer - an instrument for the real-time measurement of opticalabsorption by aerosol-particles, Sci. Total Environ., 36, 191-196, doi:10.1016/0048-9697(84)90265-1, 1984.

Herich, H., Hueglin, C., and Buchmann, B.: A 2.5 year's source apportionment study of black carbon from wood burning and fossil fuel combustion at urban and rural sites in Switzerland, Atmos. Meas. Tech., 4, 1409-1420, doi:10.5194/amt-4-1409-2011, 2011.

Heringa, M. F., DeCarlo, P. F., Chirico, R., Tritscher, T., Dommen, J., Weingartner, E., Richter, R., Wehrle, G., Prévôt, A. S. H., and Baltensperger, U.: Investigations of primary and secondary particulate matter of different wood combustion appliances with a high-resolution time-of-flight aerosol mass spectrometer, At- 
mos. Chem. Phys., 11, 5945-5957, doi:10.5194/acp-11-59452011, 2011.

Hoffmann, T., Huang, R.-J., and Kalberer, M.: Atmospheric analytical chemistry, Anal. Chem., 83, 4649-4664, doi:10.1021/ac2010718, 2011.

Huang, R.-J., Zhang, Y., Bozzetti, C., Ho, K.-F., Cao, J.-J., Han, Y., Daellenbach, K. R., Slowik, J. G., Platt, S. M., Canonaco, F., Zotter, P., Wolf, R., Pieber, S. M., Bruns, E. A., Crippa, M., Ciarelli, G., Piazzalunga, A., Schwikowski, M., Abbaszade, G., Schnelle-Kreis, J., Zimmermann, R., An, Z., Szidat, S., Baltensperger, U., El Haddad, I., and Prévôt, A. S. H.: High secondary aerosol contribution to particulate pollution during haze events in China, Nature, 514, 218-222, doi:10.1038/nature13774, 2014.

Jimenez, J. L., Canagaratna, M. R., Donahue, N. M., Prevot, A. S. H., Zhang, Q., Kroll, J. H., DeCarlo, P. F., Allan, J. D., Coe, H., Ng, N. L., Aiken, A. C., Docherty, K. S., Ulbrich, I. M., Grieshop, A. P., Robinson, A. L., Duplissy, J., Smith, J. D., Wilson, K. R., Lanz, V. A., Hueglin, C., Sun, Y. L., Tian, J., Laaksonen, A., Raatikainen, T., Rautiainen, J., Vaattovaara, P., Ehn, M., Kulmala, M., Tomlinson, J. M., Collins, D. R., Cubison, M. J., Dunlea, E. J., Huffman, J. A., Onasch, T. B., Alfarra, M. R., Williams, P. I., Bower, K., Kondo, Y., Schneider, J., Drewnick, F., Borrmann, S., Weimer, S., Demerjian, K., Salcedo, D., Cottrell, L., Griffin, R., Takami, A., Miyoshi, T., Hatakeyama, S., Shimono, A., Sun, J. Y., Zhang, Y. M., Dzepina, K., Kimmel, J. R., Sueper, D., Jayne, J. T., Herndon, S. C., Trimborn, A. M., Williams, L. R., Wood, E. C., Middlebrook, A. M., Kolb, C. E., Baltensperger, U., and Worsnop, D. R.: Evolution of organic aerosols in the atmosphere, Science, 326, 1525-1529, doi:10.1126/science.1180353, 2009.

Kelly, F. J., Fussell, J. C.: Size, source and chemical composition as determinants of toxicity attributable to ambient particulate matter, Atmos. Env., 60, 504-526, doi:10.1016/j.atmosenv.2012.06.039, 2012.

Lanz, V. A., Alfarra, M. R., Baltensperger, U., Buchmann, B., Hueglin, C., and Prévôt, A. S. H.: Source apportionment of submicron organic aerosols at an urban site by factor analytical modelling of aerosol mass spectra, Atmos. Chem. Phys., 7, 15031522, doi:10.5194/acp-7-1503-2007, 2007.

Lanz, V. A., Alfarra, M. R., Baltensperger, U., Buchmann, B., Hueglin, C., Szidat, S., Wehrli, M. N., Wacker, L., Weimer, S., Caseiro, A., Puxbaum, H., and Prevot, A. S. H.: Source attribution of submicron organic aerosols during wintertime inversions by advanced factor analysis of aerosol mass spectra, Environ. Sci. Technol., 42, 214-220, doi:10.1021/es0707207, 2008.

Lanz, V. A., Prévôt, A. S. H., Alfarra, M. R., Weimer, S., Mohr, C., DeCarlo, P. F., Gianini, M. F. D., Hueglin, C., Schneider, J., Favez, O., D'Anna, B., George, C., and Baltensperger, U.: Characterization of aerosol chemical composition with aerosol mass spectrometry in Central Europe: an overview, Atmos. Chem. Phys., 10, 10453-10471, doi:10.5194/acp-10-10453-2010, 2010.

Lee, A. K. Y., Herckes, P., Leaitch, W. R., Macdonald, A. M., and Abbatt, J. P. D.: Aqueous $\mathrm{OH}$ oxidation of ambient organic aerosol and cloud water organics: formation of highly oxidized products, Geophys. Res. Lett., 38, L11805, doi:10.1029/2011GL047439, 2011.

Mihara, T. and Mochida, M.: Characterization of solventextractable organics in urban aerosols based on mass spectrum analysis and hygroscopic growth measurement, Environ. Sci. Technol., 45, 9168-9174, doi:10.1021/es201271w, 2011.

Minguillón, M. C., Perron, N., Querol, X., Szidat, S., Fahrni, S. M., Alastuey, A., Jimenez, J. L., Mohr, C., Ortega, A. M., Day, D. A., Lanz, V. A., Wacker, L., Reche, C., Cusack, M., Amato, F., Kiss, G., Hoffer, A., Decesari, S., Moretti, F., Hillamo, R., Teinilä, K., Seco, R., Peñuelas, J., Metzger, A., Schallhart, S., Müller, M., Hansel, A., Burkhart, J. F., Baltensperger, U., and Prévôt, A. S. H.: Fossil versus contemporary sources of fine elemental and organic carbonaceous particulate matter during the DAURE campaign in Northeast Spain, Atmos. Chem. Phys., 11, 12067-12084, doi:10.5194/acp-11-12067-2011, 2011.

Mohr, C., Richter, R., DeCarlo, P. F., Prévôt, A. S. H., and Baltensperger, U.: Spatial variation of chemical composition and sources of submicron aerosol in Zurich during wintertime using mobile aerosol mass spectrometer data, Atmos. Chem. Phys., 11, 7465-7482, doi:10.5194/acp-11-7465-2011, 2011.

Mohr, C., DeCarlo, P. F., Heringa, M. F., Chirico, R., Slowik, J. G., Richter, R., Reche, C., Alastuey, A., Querol, X., Seco, R., Peñuelas, J., Jiménez, J. L., Crippa, M., Zimmermann, R., Baltensperger, U., and Prévôt, A. S. H.: Identification and quantification of organic aerosol from cooking and other sources in Barcelona using aerosol mass spectrometer data, Atmos. Chem. Phys., 12, 1649-1665, doi:10.5194/acp-12-1649-2012, 2012.

Ng, N. L., Canagaratna, M. R., Zhang, Q., Jimenez, J. L., Tian, J., Ulbrich, I. M., Kroll, J. H., Docherty, K. S., Chhabra, P. S., Bahreini, R., Murphy, S. M., Seinfeld, J. H., Hildebrandt, L., Donahue, N. M., DeCarlo, P. F., Lanz, V. A., Prévôt, A. S. H., Dinar, E., Rudich, Y., and Worsnop, D. R.: Organic aerosol components observed in Northern Hemispheric datasets from Aerosol Mass Spectrometry, Atmos. Chem. Phys., 10, 46254641, doi:10.5194/acp-10-4625-2010, 2010.

Ng, N. L., Canagaratna, M. R., Jimenez, J. L., Zhang, Q., Ulbrich, I. M., and Worsnop, D. R.: Real-time methods for estimating organic component mass concentrations from aerosol mass spectrometer data, Environ. Sci. Technol., 45, 910-916, doi:10.1021/es102951k, 2011a.

Ng, N. L., Herndon, S. C., Trimborn, A., Canagaratna, M. R., Croteau, P. L., Onasch, T. B., Sueper, D., Worsnop, D. R., Zhang, Q., Sun, Y. L., and Jayne, J. T.: An aerosol chemical speciation monitor (ACSM) for routine monitoring of the composition and mass concentrations of ambient aerosol, Aerosol Sci. Tech., 45, 780-794, doi:10.1080/02786826.2011.560211, 2011b.

Paatero, P.: The multilinear engine - a table-driven, least squares program for solving multilinear problems, including the n-way parallel factor analysis model, J. Comput. Graph. Stat., 8, 854888, doi:10.2307/1390831, 1999.

Paatero, P. and Hopke, P. K.: Rotational tools for factor analytic models, J. Chemometr., 23, 91-100, doi:10.1002/cem.1197, 2009.

Paatero, P. and Tapper, U.: Positive matrix factorization a nonnegative factor model with optimal utilization of error-estimates of data values, Environmetrics, 5, 111-126, doi:10.1002/env.3170050203, 1994.

Paatero, P., Eberly, S., Brown, S. G., and Norris, G. A.: Methods for estimating uncertainty in factor analytic solutions, Atmos. Meas. Tech., 7, 781-797, doi:10.5194/amt-7-781-2014, 2014.

Putaud, J. P., Van Dingenen, R., Alastuey, A., Bauer, H., Birmili, W., Cyrys, J., Flentje, H., Fuzzi, S., Gehrig, R., Hans- 
son, H. C., Harrison, R. M., Herrmann, H., Hitzenberger, R., Hueglin, C., Jones, A. M., Kasper-Giebl, A., Kiss, G., Kousa, A., Kuhlbusch, T. A. J., Loeschau, G., Maenhaut, W., Molnar, A., Moreno, T., Pekkanen, J., Perrino, C., Pitz, M., Puxbaum, H., Querol, X., Rodriguez, S., Salma, I., Schwarz, J., Smolik, J., Schneider, J., Spindler, G., ten Brink, H., Tursic, J., Viana, M., Wiedensohler, A., and Raes, F.: A European aerosol phenomenology-3: physical and chemical characteristics of particulate matter from 60 rural, urban, and kerbside sites across Europe, Atmos. Environ., 44, 1308-1320, doi:10.1016/j.atmosenv.2009.12.011, 2010.

Sun, Y., Zhang, Q., Zheng, M., Ding, X., Edgerton, E. S., and Wang, X.: Characterization and source apportionment of watersoluble organic matter in atmospheric fine particles $\left(\mathrm{PM}_{2.5}\right)$ with high-resolution aerosol mass spectrometry and GC-MS, Environ. Sci. Technol., 45, 4854-4861, doi:10.1021/es200162h, 2011.

Ulbrich, I. M., Canagaratna, M. R., Zhang, Q., Worsnop, D. R., and Jimenez, J. L.: Interpretation of organic components from Positive Matrix Factorization of aerosol mass spectrometric data, Atmos. Chem. Phys., 9, 2891-2918, doi:10.5194/acp-9-2891-2009, 2009.

Williams, L. R., Gonzalez, L. A., Peck, J., Trimborn, D., McInnis, J., Farrar, M. R., Moore, K. D., Jayne, J. T., Robinson, W. A., Lewis, D. K., Onasch, T. B., Canagaratna, M. R., Trimborn, A., Timko, M. T., Magoon, G., Deng, R., Tang, D., de la Rosa Blanco, E., Prévôt, A. S. H., Smith, K. A., and Worsnop, D. R.: Characterization of an aerodynamic lens for transmitting particles greater than 1 micrometer in diameter into the Aerodyne aerosol mass spectrometer, Atmos. Meas. Tech., 6, 3271-3280, doi:10.5194/amt-6-3271-2013, 2013.
Zhang, Q., Jimenez, J. L., Canagaratna, M. R., Ulbrich, I. M., Ng, N. L., and Worsnop, Y. S.: Understanding atmospheric organic aerosols via factor analysis of aerosol mass spectrometry: a review, Anal. Bioanal. Chem., 401, 3045-3067, doi:10.1007/s00216-011-5355-y, 2011.

Zotter, P., Ciobanu, V. G., Zhang, Y. L., El-Haddad, I., Macchia, M., Daellenbach, K. R., Salazar, G. A., Huang, R.-J., Wacker, L., Hueglin, C., Piazzalunga, A., Fermo, P., Schwikowski, M., Baltensperger, U., Szidat, S., and Prévôt, A. S. H.: Radiocarbon analysis of elemental and organic carbon in Switzerland during winter-smog episodes from 2008 to 2012 - Part 1: Source apportionment and spatial variability, Atmos. Chem. Phys., 14, 1355113570, doi:10.5194/acp-14-13551-2014, 2014. 